\title{
Adatok Somogy megye kétszárnyú (Diptera) faunájához
}

\author{
TÓTH SÁNDOR
}

TótH S.: Data to the fly fauna in Somogy county (Diptera)

Abstract: This paper presents some so far unpublished faunistical data of the Diptera collecting projects carried out in different regions of Somogy County since the middle of 1970's. The study contains the data of 373 species belonging to the following 7 families: Stratiomyidae (32 species), Bombyliidae (21 species), Therevidae (1 species), Tabanidae (29 species), Syrphidae (177 species), Conopidae (17 species), Tachinidae (96 species).

\section{Bevezetés}

Az elmúlt évtizedekben, kisebb-nagyobb megszakításokkal, váltakozó intenzitással folyt a kétszárnyúak (Diptera) néhány családjának gyűjtése Somogy megye egyes területein. A munkában, célzottan a kétszárnyúakra vonatkozóan, a szerzőn kívül, említésre méltó intenzitással, elsősorban Majer József, valamint kisebb mértékben Wéber Mihály, Csiby Mária és Németh Lajos vett részt. Az említetteken kívül 32 személy gyűjtött a területen több-kevesebb példányt, az ő nevük is megtalálható a gyüjtők jegyzékében, valamint rövidítve az adatközlő fejezetben. A kutatás lényegében négy kiemelt területre összpontosult. A Barcsi Borókás faunájának feltárásával kezdődött, az 1970-es évek második felében, majd folytatódott a Zselicben, a Boronka-melléki Tájvédelmi Körzetben, a Dráva-mentén (később a Duna-Dráva Nemzeti Parkban), jelenleg pedig a viszonylag kicsi Látrányi Természetvédelmi Területen.

Tekintettel azonban arra, hogy Ábrahám Levente (Somogy Megyei Múzeum Természettudományi Osztálya), ,Somogy fauna katalógusa” összeállítását tüzte ki célul, felmerült annak szükségessége, hogy a publikálatlan adatok, továbbá az elfekvő anyagok a lehetséges mértékig történő, legalább részbeni feldolgozásával, minél nagyobb mértékben járuljunk hozzá a katalógus kétszárnyúakat tartalmazó fejezetének teljesebbé tételéhez. A publikálatlan alapadatokat tartalmazó kéziratra, az időközben megjelent fauna kötet (ÁвRAнÁм 2001) „То́тH (előkészületben)” formában hivatkozik.

A fenti időszak alatt végig téma volt a Balaton partvidékén (így természetesen a somogyi parton is) a csípőszúnyog-fauna kutatása. A somogyi közöletlen csípőszúnyog alapadatok egy készülő országos faunisztikai dolgozatban jelennek meg a későbbiekben. Ugyancsak önálló dolgozat készül a Balaton, illetőleg a tó térségének (Balaton-medence) csípőszúnyog faunájáról. Ezért a jelen dolgozat nem tartalmaz csípőszúnyog adatokat. Egyébként mind a személyes gyüjtések, mind a területen müködtetett Malaisecsapdák anyagának feldolgozása a mai napig nem fejeződött be.

Az említett fauna kötetben a szerző 8 Diptera család: lószúnyogok (Tipulidae), iszapszúnyogok (Limoniidae), csípőszúnyogok (Culicidae), tőröslegyek (Therevidae), pöszörlegyek (Bombyliidae), zengőlegyek (Syrphidae), fejeslegyek (Conopidae) és fürkészlegyek (Tachinidae) anyagát dolgozta fel (TóTH 2001a, 2001b, 2001c, 2001d, 2001e, 2001f, 2001g, 2001h). A jelen dolgozat csak utóbbi 5 családdal foglalkozik, mert ezekből állnak rendelkezésre publikálatlan adatok. Szerepel viszont a dolgozatban két további olyan család is, melyeket a fauna katalógus részére Majer József állított össze 
(MAJER 2001a, 2001b), mivel a szerző rendelkezik e családokból is publikálatlan somogyi adatokkal. A szóban forgó családok a katonalegyek (Stratiomyidae) és bögölyök (Tabanidae).

A dolgozat 7 családhoz tartozó 373 faj adatait tartalmazza. Közülük az alábbiak nem szerepelnek a fauna katalógusban, vagyis Somogy faunájára újak: Therevidae: Thereva annulata (Fabricius, 1805), Tabanidae: Philipomyia graeca Fabricius, 1794, Tabanus paradoxus Jaennicke, 1866. Külön említendő a Silvius alpinus (Scopoli, 1763), melyet a Boronka-melléki Tájvédelmi Körzetből (Mély-éger, Soponyai-halastó) már közöltek (TóTH 1996), de a faunakatalógus (ÁBRAHÁM 2001) idevágó dolgozatában (MAJER 2001b) nem szerepel.

\section{Fajlista a gyüjtési adatokkal}

A közölt anyag az alábbi 86 gyüjtőhelyről származik:

\begin{tabular}{|c|c|}
\hline Álgya-berek (Balatonlelle) & Kis-Balaton (Vörs) \\
\hline Baláta-tó (Szenta) & Kis-gyótai-erdő (Marcali) \\
\hline Balatonberény & Kishárságy (Somogyhárságy) \\
\hline Balatonboglár & Középrigóc (Barcs) \\
\hline Balatonfenyves & Kúti-őrház (Darány) \\
\hline Balatonföldvár & Lankóci-erdő (Gyékényes) \\
\hline Balatonkiliti (Siófok) & Lengyeltóti \\
\hline Balatonlelle & Lipótfa (Bárdudvarnok) \\
\hline Balatonőszöd & Lugi-erdő (Potony) \\
\hline Balatonszemes & Lugi-erdő (Tótújfalu) \\
\hline Bankó-hegy (Zselickisfalud) & Marcali \\
\hline Barcsi-borókás (Barcs) & Márcadópuszta (Zselickisfalud) \\
\hline Barcsi-borókás (Darány) & Máriaasszony-sziget (Vörs) \\
\hline Berki-erdő (Bélavár) & Mély-éger (Mesztegnyő) \\
\hline Bélatelep (Fonyód) & Mély-égeri-halastó (Mesztegnyő) \\
\hline Boronka (Marcali) & Nagybajom \\
\hline Böhönye & Nagy-berek (Darány) \\
\hline Bőszénfa & Nagy-gyótai-erdő (Marcali) \\
\hline Cseberki-erdő (Bárdudvarnok) & Nyugati-berek (Balatonberény) \\
\hline Csikota (Darány) & Örtilos \\
\hline Csurgó & Örtilos-vasútállomás (Örtilos) \\
\hline Csurgós-kúti-völgy (Zselickisfalud) & Palinai-erdő (Bélavár) \\
\hline Darány & Pap-erdő (Barcs) \\
\hline Dennai-erdészlak (Szenna) & Péterhida \\
\hline Denna-erdő (Szenna) & Potony \\
\hline Dráva-hullámtér (Vízvár) & Pusztafalusi-dűlő (Péterhida) \\
\hline Enyezdi-rakodó (Zselickisfalud) & Raglári-erdő (Patca) \\
\hline Erdei-dűlő (Péterhida) & Ropolypuszta (Bőszénfa) \\
\hline Erdősház-I. (Böhönye) & Siófok \\
\hline Farkaslaki-erdő (Bőszénfa) & Somogytarnóca \\
\hline Felsőkak (Mesztegnyő) & Soponyai-halastó (Mesztegnyő) \\
\hline Felsőszentmárton & Szenna \\
\hline Galabárdpuszta (Nagybajom) & Szentmihályhegy Örtilos) \\
\hline Gólyás-berek (Főnyed) & Szenttamási-irtás (Bőszénfa) \\
\hline Holt-Dráva (Bélavár) & Szerenkei-erdő (Magyarlukafa) \\
\hline Homokpuszta (Nagybajom) & Tóközpuszta (Zamárdi) \\
\hline Hosszúvíz & Tótújfalu \\
\hline Igal & Töröcske (Kaposvár) \\
\hline Inke & Vízvár \\
\hline Kaposvár & Vörös-domb (Zselickisfalud) \\
\hline Kardosfapuszta (Zselickisfalud) & Vörs \\
\hline Kerék-hegy (Bélavár) & Zákány \\
\hline Kétnyári-berek Somogyudvarhely) & Zamárdi \\
\hline
\end{tabular}


A gyűjtőhelyeket a szemléletesség kedvéért, a Dévai György és munkatársai által készített UTM hálótérképen (1. ábra) is ábrázoljuk (DÉVAI et al. 1996). A térképen a fekete körök a jelen dolgozatban szereplö lelőhelyeket jelölik.

A gyűjtők és nevük rövidítése:

$\begin{array}{ll}\text { Ismeretlen gyüjtő } & \text { A } \\ \text { Ábrahám Levente } & \text { ÁL } \\ \text { Babos Margit } & \text { BM } \\ \text { Benedek Pál } & \text { BP } \\ \text { Bessenyi Ferenc } & \text { BF } \\ \text { Csiby Mária } & \text { CSM } \\ \text { Dózsa } & \text { DÓ } \\ \text { Endrődy Sebő } & \text { ES } \\ \text { Gebhardt Antal } & \text { GA } \\ \text { Horn Artúrné } & \text { HA } \\ \text { Jermy Tibor } & \text { JT } \\ \text { Józan Zsolt } & \text { JZS } \\ \text { Kasper Ágota } & \text { KÁ } \\ \text { Kaszab Zoltán } & \text { KZ } \\ \text { Kondorosy Előd } & \text { KE } \\ \text { Majer József } & \text { MJ } \\ \text { Martinovich Valér } & \text { MV } \\ \text { Méhes } & \text { MÉ } \\ \text { Mihályi Ferenc } & \text { MF } \\ \text { Móczár László } & \text { ML } \\ \text { Neiger M. } & \text { NM } \\ \text { Németh Lajos } & \text { NL }\end{array}$

$\begin{array}{ll}\text { Olajos Viola } & \text { OV } \\ \text { Papp A. } & \text { PA } \\ \text { Papp László } & \text { PL } \\ \text { Pelle József } & \text { PJ } \\ \text { Petrovics Zsuzsanna } & \text { PZS } \\ \text { Sáringer Gyula } & \text { SGY } \\ \text { Soós Árpád } & \text { SÁ } \\ \text { Szalóki Dezső } & \text { SZD } \\ \text { Szilády Zoltán } & \text { SZI } \\ \text { Szőcs József } & \text { SZÖ } \\ \text { Tót Ilona } & \text { TI } \\ \text { Tóth Sándor } & \text { TS } \\ \text { Uherkovich Ákos } & \text { UÁ } \\ \text { Vásárhelyi Tamás } & \text { VT } \\ \text { Visnyovszky Éva } & \text { VÉ } \\ \text { Wéber Mihály } & \text { WM }\end{array}$

Egyéb rövidítések:

Fénycsapdával (lámpázással gyüjtve) $=+$ FÉNY

Malaise-csapdával gyüjtve $=+$ MAL

Tálcsapdával (sárgatál) gyüjtve $=+\mathrm{TÁL}$

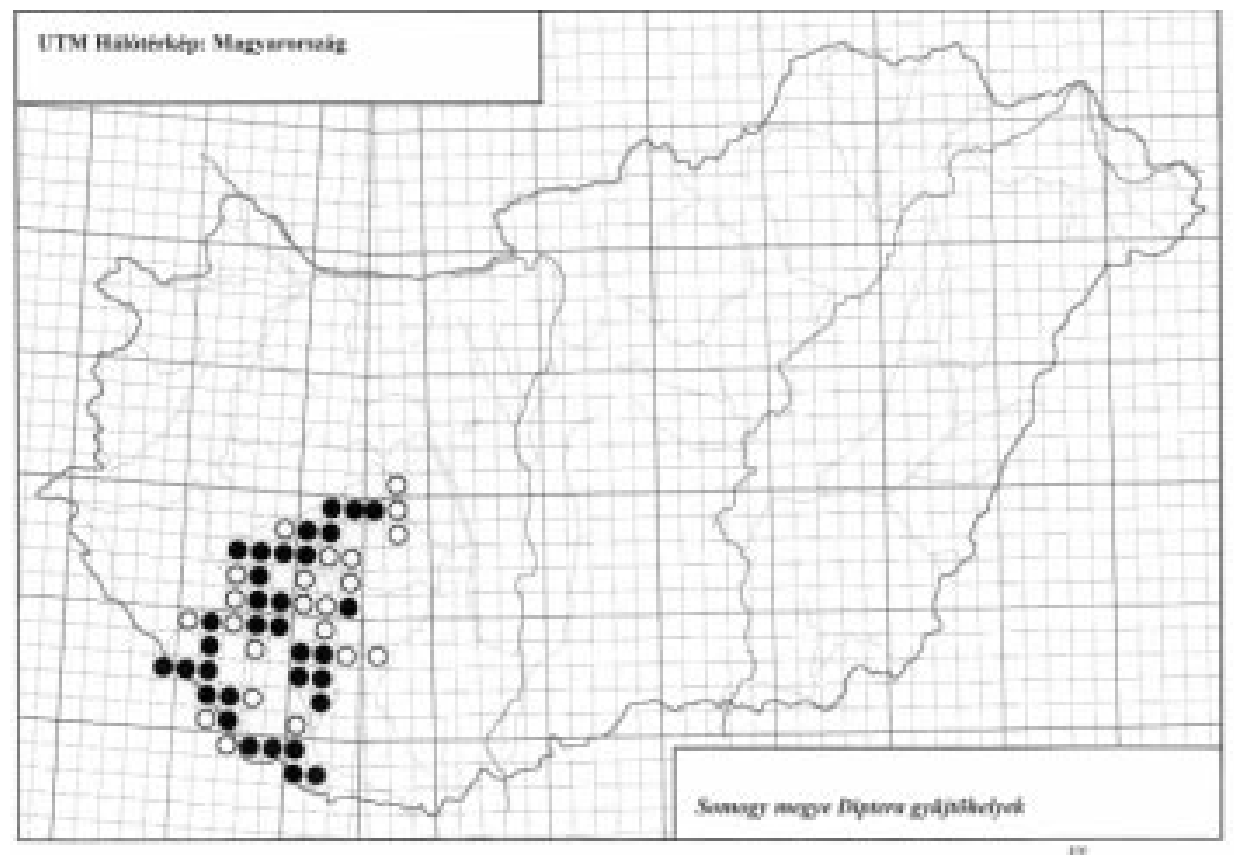

1. ábra: Kétszárnyúak gyűjtőhelyei Somogy megyében Magyarország UTM hálótérképén, 10x10 km-es négyzetek szerinti bontásban 


\section{Katonalegyek (Stratiomyidae)}

A dolgozat 32 faj adatait tartalmazza. $\mathrm{Az}$ újabb rendszertani munkákban a Xylomyidae alcsalád önálló családként szerepel.

\section{Xylomyidae}

Solva marginata (Meigen, 1820) - Örtilosvasútállomás: 1993.05.18., 1@, TS, +MAL; 1993.05.22., 2Q, TS, +MAL; 1993.05.26., 3O, TS, +MAL; 1993.06.17., 7Q, TS, +MAL; 1993.06.25., 1\%, TS, +MAL; 1993.07.01., 30 13Q, TS, +MAL; 1993.07.03., 40 560, TS, +MAL; 1993.07.08., $10^{\star}$ 12ᄋ, TS, +MAL; 1993.07.11., 2ᄋ, TS, +MAL; 1993.07.15., 6O, TS, +MAL; 1993.07.19., 14ㅇ, TS, +MAL; 1993.07.23., $10^{\pi} 60, \quad \mathrm{TS}, \quad+\mathrm{MAL}$; 1993.07.28., 11O, TS, +MAL; 1993.08.02., 3O, TS, +MAL - Ropolypuszta: 1980.08.06., 4ᄋ, TS; 1988.07.14., 3Q, TS, +MAL; 1988.07.22., $10^{\Uparrow} 4$, TS, +MAL - Soponyai-halastó: 1991.06.21., 1@, TS, +MAL; Vízvár: 1992.08.15., 4ᄋ, TS, +MAL.

\section{Stratiomyidae}

Actina chalybea Meigen, 1804 - Kis-gyótaierdő: 1991.05.30., 1Q, TS - Lankóci-erdő: 1993.05.04., 20 $0^{\star}$, TS; 1996.05.10., 360 190, TS Lipótfa: 1986.05.09., 10 $0^{\star}$, TS - Örtilos-vasútállomás: 1993.04.27., $60^{\star} \quad 2$, $\mathrm{TS}, \quad+\mathrm{MAL}$; 1993.05.02., $10^{\pi} 1$, TS, +MAL; 1993.05.06., $20^{\star}$ 3Q, TS, +MAL - Ropolypuszta: 1988.05.18., $20^{\star}$ 10, TS, +MAL

Allognosta vagans (Loew, 1873) - Örtilosvasútállomás: 1993.06.25., 1Q, TS, +MAL; 1993.07.01., 10, TS, +MAL; 1993.07.03., 3o, TS, +MAL; 1993.07.08., 1Q, TS, +MAL; 1993.07.15., 2ᄋ, TS, +MAL.

Beris chalybata (Forster, 1761) - Barcsi-Borókás (Barcs): 1977.05.02., 10 10, TS - Lankóci-erdő: 1993.04.28., 70 20, TS; 1993.05.04., 2ᄋ, TS Nagy-gyótai-erdő: 1992.04.15., 10 $0^{\star}$, TS - Örtilosvasútállomás: 1993.05.02., 4Q, TS, +MAL; 1993.05.06., $10^{\star}$ 50, TS, +MAL; 1993.05.10., 1o, TS, +MAL - Potony: 1977.05.03., 3o, KÁ; 1977.05.03., 2Q, TS - Ropolypuszta: 1988.05.20., $20^{\star} 10, \mathrm{TS},+\mathrm{MAL}$

Beris clavipes (Linné, 1767) - Ropolypuszta: 1988.05.18., $10^{\star}$ 4ᄋ, TS, +MAL.

Beris fuscipes Meigen, 1820 - Ropolypuszta:
1988.06.21., $10^{\pi} 10, \mathrm{TS},+\mathrm{MAL}$.

Beris morrisii Dale, 1841 - Örtilos-vasútállomás: 1993.05.10., $10^{\star} 1$ 1 , TS, +MAL - Ropolypuszta: 1980.05.29., $10^{\star} 1 \mathrm{Q}$, TS.

Chloromyia formosa (Scopoli, 1763) Balatonberény: 1984.07.03., 10, SGY Balatonfenyves: 1984.087.18., 1Q, SGY - BarcsiBorókás (Darány): 1982.08.31., 1Q, TS - Kúti-őrház: 1984.06.20., 1O, PZS - Örtilos-vasútállomás: 1993.05.18., 10 $0^{\pi}$, TS, +MAL; 1993.06.17., $20^{\star} 10$, TS, +MAL; 1993.06.21., 10, TS, +MAL; 1993.07.01., $20^{\star}$ 3Q, TS, +MAL; 1993.07.03., 30 2ᄋ, TS, +MAL; 1993.07.08., 1O, TS, +MAL; 1993.07.11., 20 $0^{\star}$, TS, +MAL; 1993.07.15., 40 20 TS, +MAL; 1993.07.19., $10^{\pi} 20$, TS, +MAL; 1993.07.23., 10 30, TS, +MAL; 1993.07.28., 10, TS, +MAL; 1993.08.02., 1O, TS, +MAL Péterhida: 1994.06.25., 30 $0^{\star}$, TS - Potony: 1976.06.12., $20^{\pi} 10$, TS - Ropolypuszta: 1980.08.06., $10^{\pi} 10$, TS; 1988.05.27., 1O, TS, +MAL; 1988.06.06., 1\%, TS, +MAL; 1988.06.21., $10^{\top}, \mathrm{TS},+\mathrm{MAL} ; 1988.06 .20 ., 10, \mathrm{TS},+\mathrm{MAL}$; 1988.06.26., 10 $0^{\pi}$, TS, +MAL; 1988.06.30., $10^{\pi} 20$, TS, +MAL; 1988.07.04., 1O, TS, +MAL; 1988.07.11., 1Q, TS, +MAL - Siófok: 1984.06.30., 10, SGY; 1985.07.04., 2Q, SGY - Vízvár: 1992.06.15., $10^{\pi}$ 1O, TS, +MAL; 1992.07.15., 10 TS, +MAL; 1992.08.15., 10, TS, +MAL - Zamárdi: 1974.07.11., 10 $0^{\pi}, \mathrm{ML}$.

Chloromyia speciosa (Macquart, 1834) - Álgyaberek: 1989.06.26., 10, TS - Lankóci-erdő: 1993.05.27., 1O, TS - Ropolypuszta: 1988.06.10., $20^{\pi} 10$, TS, +MAL; 1988.06.21., 1O, TS, +MAL; 1988.06.30., $10^{\pi}$ 2Q, TS, +MAL.

Chorisops tibialis (Meigen, 1820) - Örtilosvasútállomás: 1993.09.05., 1O, TS, +MAL Ropolypuszta: 1988.05.18., $10^{\star} 10, \mathrm{TS},+\mathrm{MAL}$.

Clitellaria ephippium (Fabricius, 1775) Lankóci-erdő: 1993.05.04., 10 1\%, TS; 1993.05.27., 1Q, TS - Lugi-erdő (Potony): 1973.05.09., 10, TS. Eupachygaster tarsalis (Zetterstedt, 1842) Örtilos-vasútállomás: 1993.07.03., 10, TS, +MAL. Lasiopa villosa (Fabricius, 1794) Ropolypuszta: 1988.07.27., $10^{\pi} 10$, TS, +MAL Soponyai-halastó: 1991.07.31., 1@, TS

Microchrysa polita (Linnaeus, 1758) - Örtilosvasútállomás: 1993.05.18., 1O, TS, +MAL; 1993.07.03., 110, TS, +MAL; 1993.07.08., 8O, TS, 


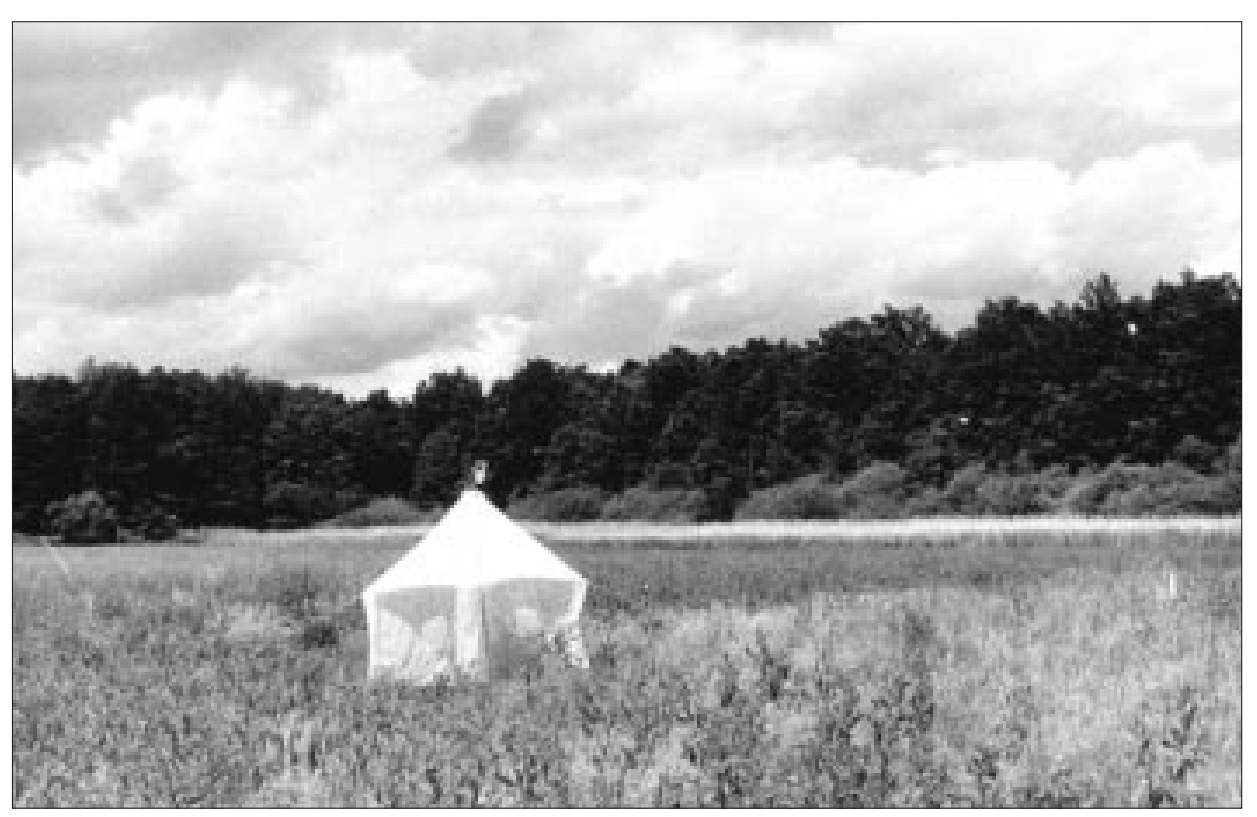

2. ábra: A szerző Malaise-csapdája a Boronka-melléki Tájvédelmi Körzetben (Mély-éger)

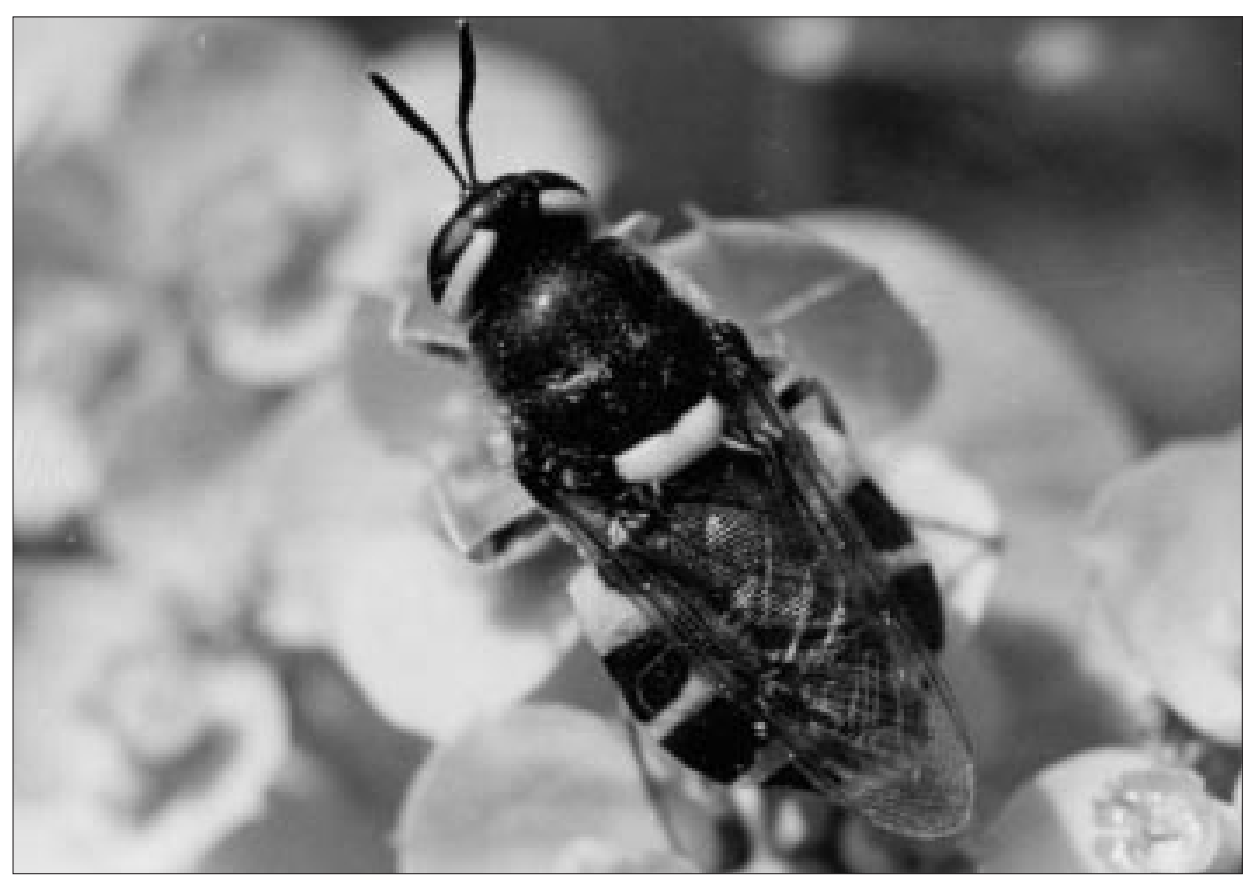

3. ábra: Stratiomys chamaeleon (Stratiomyidae) 
+MAL; 1993.07.11., 2Q, TS, +MAL; 1993.07.15. 8Q, TS, +MAL; 1993.07.19., 50, TS, +MAL; 1993.07.23., 9ᄋ, TS, +MAL; 1993.07.28., 7@, TS, +MAL; 1993.08.07., 2ᄋ, TS, +MAL; 1993.08.17., 1\%, TS, +MAL - Vízvár: 1992.06.15., 2Q, TS, +MAL; 1992.07.15., 4Q, TS, +MAL; 1992.08.15., 10, TS, +MAL.

Nemotelus pantherinus (Linnaeus, 1758) Balatonboglár: 1984.07.06., $10^{\star} 10$, SGY Balatonfenyves: 1984.07.06., 1Q, SGY Balatonlelle: 1984.07.06., 1@, SGY.

Odontomyia argentata (Fabricius, 1794) Lencsenpusztai-halastó: 1990.04.11., 1@, NL.

Odontomyia ornata (Meigen, 1822) - Lankócierdő: 1993.05.04., $10^{\star} 1 \%$, TS - Mély-éger: 1991.07.10., 10 , TS - Palinai-erdő: 1993.05.04., 2Q, TS.

Odontomyia tigrina (Fabricius, 1775) -

Kardosfapuszta: 1984.07.22., 1@, TS - Palinai-erdő: 1993.05.04., 10 $0^{\pi}$, TS.

Oplodontha viridula (Fabricius, 1775) Lankóci-erdő: 1993.04.28., 1@, TS - Örtilos-vasútállomás: 1993.07.15., 10 $0^{\star}, \mathrm{TS},+\mathrm{MAL}$.

Oxycera leonina (Panzer, [1798]) - Hosszúvíz: 1991.05.14., 2Q, TS, +MAL - Kardosfapuszta: 1984.07.22., 10 10, TS - Örtilos-vasútállomás: 1993.07.28., 1O, TS, +MAL; 1993.08.02., 1O, TS, +MAL - Ropolypuszta: 1980.08.06., 1Q, TS; 1988.08.14., 1o, TS, +MAL.

Oxycera nigricornis Olivier, 1812 - Örtilosvasútállomás: 1993.07.15., 1O, TS, +MAL; 1993.07.28., 10, TS, +MAL.

Oxycera pygmaea (Fallén, 1817) - Örtilosvasútállomás: 1993.07.15., 1O, TS, +MAL; 1993.07.28., 10, TS, +MAL.

Oxycera trilineata (Fabricius 1781) Ropolypuszta: 1988.07.14., 10, TS, +MAL.

Pachygaster atra (Panzer, [1798]) Balatonfenyves: 1984.08.15., 1@, SGY - Hosszúvíz: 1991.07.10., 10, TS, +MAL - Kardosfapuszta: 1984.07.22., 10 $0^{\star}$, TS - Örtilos-vasútállomás: 1993.07.01., 5o, TS, +MAL; 1993.07.03., 6Q, TS, +MAL; 1993.07.08., 14ᄋ, TS, +MAL; 1993.07.15., 6ᄋ, TS, +MAL; 1993.07.19., 80, TS, +MAL; 1993.07.23., 9ᄋ, TS, +MAL; 1993.07.28., 6O, TS, +MAL - Ropolypuszta: 1988.06.20., $10^{\star} 2 \mathrm{O}, \mathrm{TS}$, +MAL; 1988.06.21., $10^{\pi} 10, \quad \mathrm{TS}, \quad+\mathrm{MAL}$; 1988.06.26., 3o, TS, +MAL; 1988.06.30., $10^{\Uparrow}$ 3o, TS, +MAL; 1988.07.03., 2O, TS, +MAL; 1988.07.04., $10^{\star}$ 5Q, TS, +MAL; 1988.07.11., 3o,
TS, +MAL; 1988.07.14., $10^{\pi}$ 2O, TS, +MAL; 1988.07.22., 4O, TS, +MAL; 1988.07.27., 1O, TS, +MAL - Vízvár: 1992.07.15., 4Q, TS, +MAL; 1992.08.15., 4O, TS, +MAL.

Pachygaster leachi (Curtis, 1824) - Hosszúvíz: 1991.07.10., 1Q, TS, +MAL; 1991.07.14., 1@, TS, +MAL - Örtilos-vasútállomás: 1993.06.17., 30, TS, +MAL; 1993.06.21., 30, TS, +MAL; 1993.06.25., 3O, TS, +MAL; 1993.07.01., 3O, TS, +MAL; 1993.07.03., 14Q, TS, +MAL; 1993.07.08., 21@, TS, +MAL; 1993.07.11., 3O, TS, +MAL; 1993.07.15., 7Q, TS, +MAL; 1993.07.15., 12Q, TS, +MAL; 1993.07.23., 21@, TS, +MAL; 1993.07.28., 14ᄋ, TS, +MAL; 1993.08.02., 50, TS, +MAL; 1993.08.17., 1\%, TS, +MAL - Ropolypuszta: 1988.07.14., 10 $0^{\star}$, TS, +MAL; 1988.07.27., 10 10 10, TS, +MAL - Vízvár: 1992.07.15., 4ᄋ, TS, +MAL; 1992.08.15., 3ᄋ, TS, +MAL

Sargus bipunctatus (Scopoli, 1763) - Örtilosvasútállomás: 1993.09.10., 1@, TS, +MAL Ropolypuszta: 1988.08.14., 10, TS, +MAL.

Sargus cuprarius (Linnaeus, 1758) - Örtilosvasútállomás: 1993.07.08., 1@, TS, +MAL.

Sargus iridatus (Scopoli, 1763) - Örtilos-vasútállomás: 1993.05.18., 10, TS, +MAL - Ropolypuszta: 1988.08.14., 10, TS, +MAL.

Stratiomys chamaeleon (Linnaeus, 1758) Ropolypuszta: 1980.08.06., 10, TS.

Stratiomys potamida Meigen, 1822 - Mély-éger: 1991.07.10., 10 $0^{\pi}$, TS.

Stratiomys singularior (Harris, [1776]) Soponyai-halastó: 1991.07.31., 10, TS.

Zabrachia minutissima (Zetterstedt, 1838) Örtilos-vasútállomás: 1992.07.26., 10 $0^{\star}$, TS, +MAL; 1992.07.28., 1O, TS, +MAL.

\section{Pöszörlegyek (Bombyliidae)}

A dolgozat 21 Bombyliidae faj adatait tartalmazza.

Anthrax leucogaster Wiedemann in Meigen, 1820 - Berki-erdő: 1995.07.10., 20, TS - Hosszúvíz: 1991.07.14., 1O, TS, +MAL - Lugi-erdő (Potony): 1995.07.11., 10 , TS - Palinai-erdő: 1975.07.10., 1O, TS - Ropolypuszta: 1998.07.22., 10 , TS, +MAL. Anthrax varius Fabricius, 1794 - Darány: 1982.06.23., 40 , BF.

Bombylius ater Scopoli, 1763 - Lankóci-erdő: 1995.07.10., 3o, TS - Ropolypuszta: 1980.05.29., $10^{\pi} 1$, TS. 


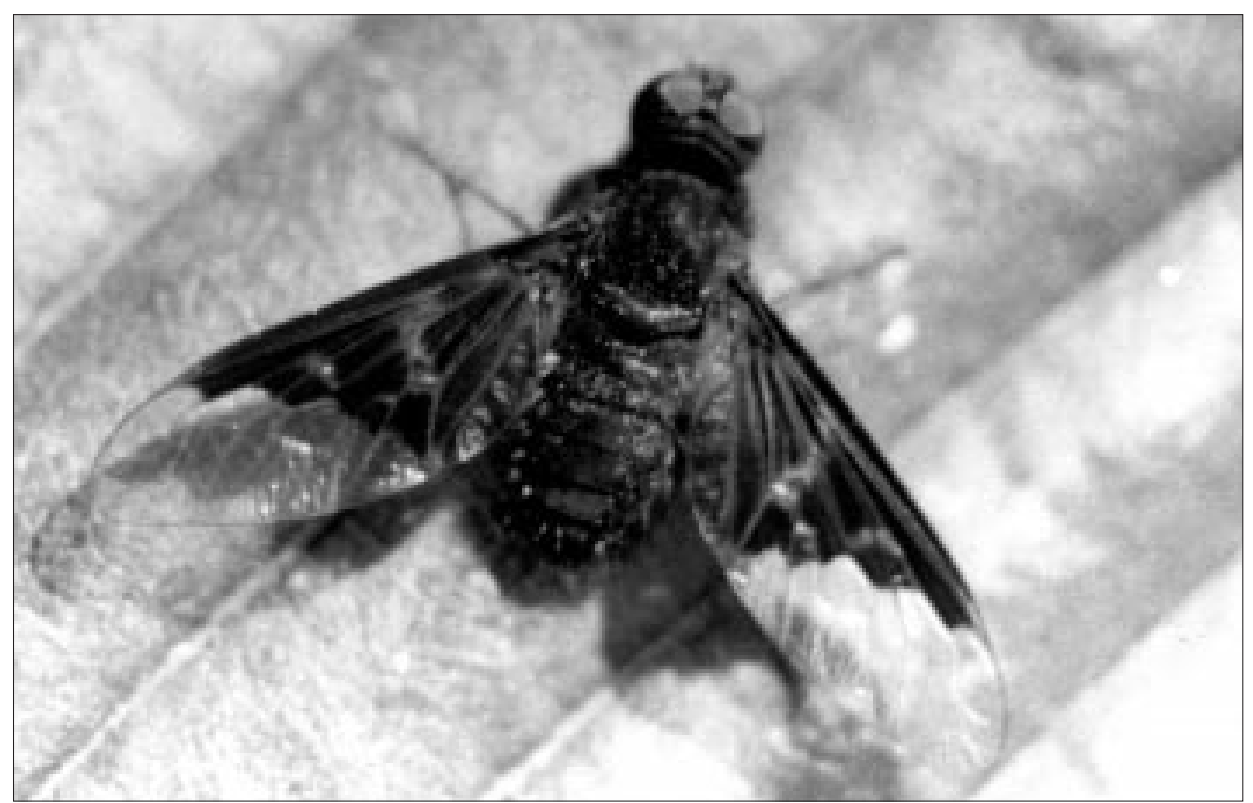

\section{3. ábra: Hemipenthes morio (Bombyliidae)}

Bombylius canescens Mikan, 1796 - Potony: 1977.05.03., 10 $0^{\top}$, TS - Ropolypuszta: 1980.05.29., 3o, CSM; 1980.05.29., $10^{\star} 20$, TS - Szenna: 1986.05.09., 1Q, TS - Zselickisfalud: 1986.05.09., $10^{\pi}$, TS.

Bombylius cinerascens Mikan, 1796 - Lankócierdő: 1996.05.10., 10 3o, TS - Potony: 1973.05.09., $30^{\pi} 20$, TS.

Bombylius discolor Mikan, 1796 - Lankóci-erdő: 1995.05.03., 20 10, TS - Lugi-erdő (Potony): 1995.05.04., 20 , TS - Szenna: 1986.05.09., $10^{\star} 20$, TS - Potony: 1973.05.09., 20 $0^{\star}$, TS.

Bombylius fimbriatus Meigen, 1820 - Lankócierdő: 1995.05.03., 30 60, TS - Örtilos: 1995.05.03., 1ㅇ, TS - Palinai-erdő: 1995.05.03., 4Q, TS Szentborbás: 1997.05.06., $20^{\star} 1$ 1, TS.

Bombylius major Linnaeus, 1858 - Berki-erdő: 1995.05.04., 3o,, TS - Csurgós-kúti-völgy: 1987.05.25., 10 $0^{\star}$, TS - Denna-erdő: 1987.05.15., 20, TS - Erdei-dúlő: 1995.05.03., $20^{\star}$ 70, TS Lankóci-erdő: 1995.05.03., $20^{\star} \quad 110$, TS; 1996.05.10., $10^{\star} 2 \mathrm{O}$, TS - Lugi-erdő (Tótújfalu): 1997.05.06., 30 7Q, TS - Örtilos: 1995.05.03., 40 7Q, TS - Örtilos-vasútállomás: 1993.04.27., $10^{\star}$ 1\%, TS, +MAL - Pusztafalusi-dűlő: 1995.05.03., 4Q, TS
- Ropolypuszta: 1980.05.29., $10^{\star} 2$ 2Q, TS Szentborbás: 1997.05.06., 70 4Q, TS.

Bombylius venosus Mikan, 1796 - Lankóci-erdő: 1995.05.03., $20^{*}$ 1o, TS.

Bombylius vulpinus Wiedemann in Meigen, 1820 - Pusztafalusi-dúlő: 1995.07.04., 20 10, TS. Bombylosoma nigriceps (Loew, 1862) - Barcsi Borókás: 1978.07.04., 10 , PL. Bombylosoma unicolor (Loew, 1855) - Örtilosvasútállomás: 1993.07.03., 10 , TS, +MAL.

Conophorus virescens (Fabricius, 1787) Lankóci-erdő: 1996.05.10., $20^{\star} 1$ 1 , TS.

Hemipenthes morio (Linnaeus, 1758) - Erdei-dülő: 1995.07.04., 1Q, TS - Lankóci-erdő: 1995.07.10., $40^{\star}$ 6O, TS - Lugi-erdő: 1995.07.11., 20 $0^{\star}$, TS Palinai-erdő: 1995.07.10., $10^{\pi}$ 3Q , TS; 1996.08.10., 3o, TS.

Lomatia sabaea (Fabricius, 1781) - Lankócierdő: 1995.07.10., 2Q, TS - Lugi-erdő: 1995.07.11., $30^{\pi} 10$, TS.

Phthiria canescens Loew, 1846 - Berki-erdö:

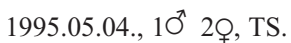

Spogostylum aethiops (Fabricius, 1781) -

Ropolypuszta: 1988.07.22., 10 , TS, +MAL. Systoechus gradatus (Wiedemann in Meigen, 1820) - Bélavár: 1996.06.27., 10, KE. Villa circumdata (Meigen, 1820) - Lankóci-erdő: 


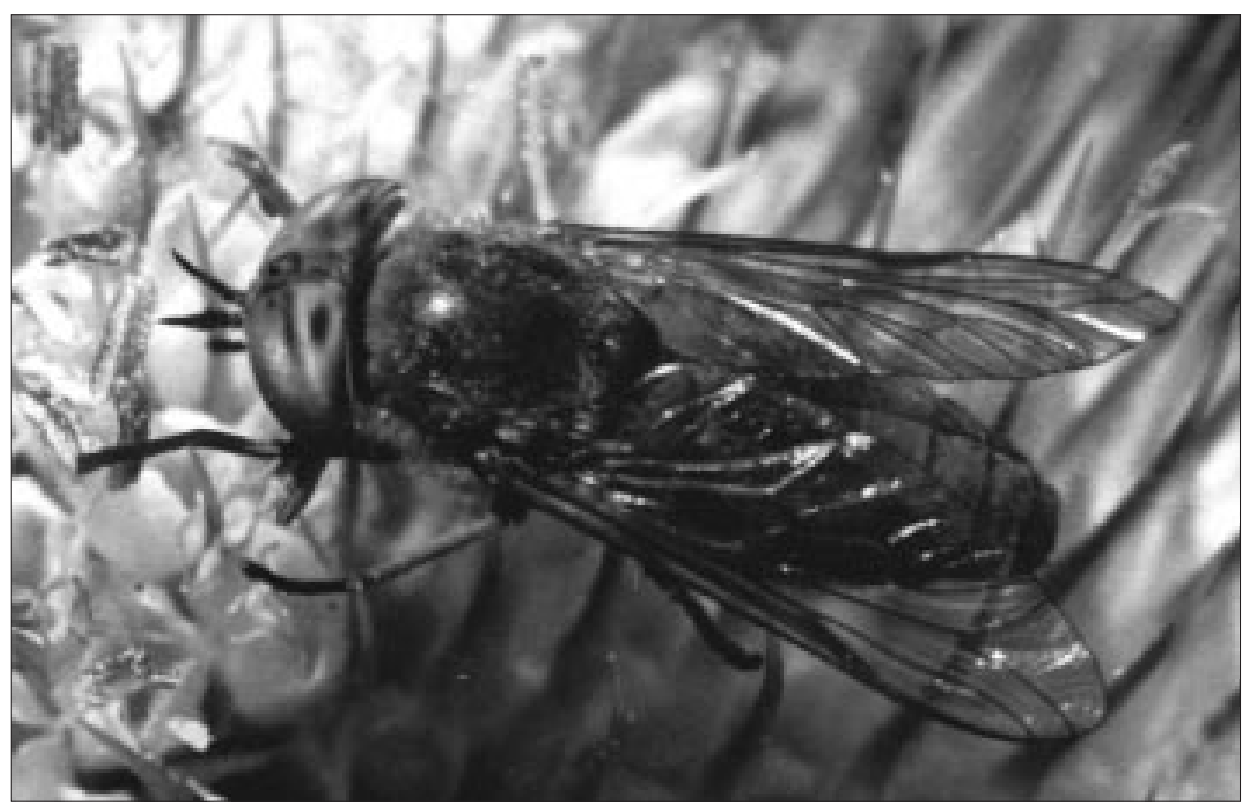

\section{4. ábra: Atylotus rusticus (Tabanidae)}

1995.07.10., $10^{\star}, \quad$ TS - Pusztafalusi-dűlő: 1995.07.04., $10^{\star}$, TS.

Villa halteralis (Kowarz, 1883) - Örtilos-vasútállomás: 1993.08.02., 10, TS, +MAL.

Villa hottentotta (Linnaeus, 1758) - Barcsi Borókás: 1978.08.27., 10, TS; 1986.08.11., 10 , TS Berki-erdő: 1995.07.10., $10^{\pi}$ 3O, TS - Darány: 1982.06.23., 20 $0^{\pi}$, BF; 1982.06.26., 1Q, TS - Erdeidűlő: 1995.07.04., $10^{\star}$ 3ơ, TS - Holt-Dráva (Bélavár): 1995.09.04., 4Qి, TS - Kétnyári-berek: 1995.07.10., $10^{\pi} 2$ Q,$\quad$ TS - Lankóci-erdő: 1995.07.10., 30 1Q, TS - Lugi-erdő (Potony): 1995.07.11., 30 4O TS - Őrtilos-vasútállomás: 1993.08.02., 10, TS, +MAL - Palinai-erdő: 1975.07.10., $20^{\star} 10$, TS - Ropolypuszta: 1979.07.08., $10^{\top} 1$ 1Q, CSM; 1980.07.06., 1Q, TS; 1980.08.06., 3Q, TS

\section{Tőröslegyek (Therevidae)}

A dolgozat egy régi gyűjtés alapján, egyetlen faj adatát tartalmazza, mely azonban Somogy faunájára új.

Thereva annulata (Fabricius, 1805) - Zamárdi: 1957.08.15-20., 10 , KZ.

\section{Bögölyök (Tabanidae)}

A dolgozat 29 bögöly faj adatait tartalmazza, közülük 2 (Philipomyia graeca, Tabanus paradoxus) új Somogy faunájára.

Atylotus fulvus (Meigen, 1820) - Máriaasszonysziget: 1996.06.11., $20^{\star} 50$, TS.

Atylotus loewianus Villeneuve, 1920 - Gólyásberek: 1995.07.31., 2Q, TS, +MAL - Ropolypuszta: 1980.08.06., 9ᄋ, CSM; 1980.08.06., 30 16@, TS; 1985.08.04., 7Q, TS - Soponyai-halastó: 1991.07.31., 10, TS.

Atylotus rusticus (Linné, 1767) - Gólyás-berek: 1995.07.31., $20^{\star}$ 3O, TS, +MAL - Máriaasszonysziget: 1996.06.11., 30 70, TS - Ropolypuszta: 1980. 08.06., 1ㅇ, TS.

Chrysops caecutiens (Linnaeus, 1758) - Máriaasszony-sziget: 1996.06.11., $10^{\pi} \quad 40, \quad \mathrm{TS}-$ Ropolypuszta: 1980.08.06., 3o, CSM; 1980.08.06., $10^{\pi} 7$, TS; 1980.08.06., 5O, TS, +MAL; 1980. 08.07., $10^{\star}$ 7O , TS, +MAL; 1982.06.27., 2Q, TS.

Chrysops flavipes Meigen, 1804 - Gólyás-berek: 1995.07.31., 3@, TS, +MAL - Zamárdi: 1953.08.25., 3O, MF. 
Chrysops viduatus (Fabricius, 1794) - Gólyásberek: 1995.07.31., 3O, TS, +MAL - Máriaasszonysziget: 1996.06.11., 50, TS - Potony: 1976.06.12., 1\%, TS - Ropolypuszta: 1980.08.06., 50, CSM; 1980.08.06., 3O, TS; 1980.08.06., $20^{\star} 60$, TS, + MAL.

Haematopota italica Meigen, 1804 - Gólyás-berek: 1995.07.31., 1Q, TS, +MAL - Máriaasszonysziget: 1996.06.11., 2Q, TS - Ropolypuszta: 1980.08.06., 4ㅇ, CSM; 1980.08.06., 1@, TS, +MAL; 1980.08.07., 10 12Q, TS, +MAL; 1982.06.27., 3Q, TS; 1985.08.14., $10^{\star} 30$, TS.

Haematopota pluvialis (Linnaeus, 1758) Álgya-berek: 1989.06.26., 1@, TS - Homokpuszta: 1990.07.20., $30^{\pi} 24$, NL - Kis-gyótai-erdő: 1991.05.30., 1@, TS - Máriaasszony-sziget: 1996.06.11., $20^{\pi} 230$, TS - Ropolypuszta: 1980.08.06., 9O, CSM; 1980.08.06., 30, TS; 1980.08.06., $20^{\star}$ 16Q, TS, +MAL; 1980.08.07., 21@, TS, +MAL; 1985.08.14., 2O, TS - Soponyai-halastó: 1990.07.20., 10Q, NL.

Haematopota scutellata (Olsufjev, Moucha \& Chvala, 1964) - Máriaasszony-sziget: 1996.06.11., 1@, TS - Ropolypuszta: 1985.08.14., 1@, TS (gépkocsiba repült).

Heptatoma pellucens (Fabricius, 1776) - Gólyásberek: 1995.07.31., 20 23O, TS, +MAL - Máriaaszszony-sziget: 1996.06.11., 2O, TS - Ropolypuszta: 1980.08.06., 7@, CSM; 1980.08.06., 10, TS.

Hybomitra acuminata (Loew, 1858) - Máriaaszszony-sziget: 1996.06.11., $30^{\star} 50$, TS.

Hybomitra bimaculata (Macquart, 1826) Soponyai-halastó: 1991.05.31., 1Q, TS Ropolypuszta: 1988.05.30., 20 10, TS, +MAL.

Hybomitra ciureai (Séguy, 1937) - Gólyás-berek: 1995.07.31., 10 120, TS, +MAL - Máriaaszszony-sziget: 1996.06.11., 8Q, TS -Ropolypuszta: 1980.08.06., 5Q, CSM; 1980.08.06., 2Q, TS Soponyai-halastó: 1991.06.21., 3O, TS, +MAL Ropolypuszta: 1988.07.14., 1@, TS, +MAL.

Hybomitra distinguenda (Verrall, 1909) - Gólyás-berek: 1995.07.31., 4Q, TS, +MAL Ropolypuszta: 1988.07.14., 1@, TS, +MAL.

Hybomitra muehlfeldi (Brauer in Brauer \& Bergenstamm, 1880) - Ropolypuszta: 1980.08.06., 1o, CSM; 1980.08.06., 1ㅇ, TS.

Hybomitra pilosa (Loew, 1858) - Bőszénfa: 1973.05.14., 1@, UÁ - Farkaslaki-erdő: 1973.05.14., 2ᄋ, UÁ - Ropolypuszta: 1988.05.24., $30^{\star} 1$ 1 , TS, + MAL.
Philipomyia graeca Fabricius, 1794 Ropolypuszta: 1985.08.14., 1Q, TS (gépkocsiba repült). Silvius alpinus (Scopoli, 1763) - Kis-gyótaierdő: 1991.05.30., 1Q, TS - Ropolypuszta: 1980.08.06., 1O, CSM; 1985.08.14., 1o, TS (gépkocsiba repült).

Tabanus autumnalis Linnaeus, 1761 - Gólyásberek: 1995.07.31., 1Q, TS, +MAL - Máriaasszonysziget: 1996.06.11., $20^{\pi} 10$, TS -Ropolypuszta: 1980.08.06., 1@, CSM; 1980.08.06., 2o, TS.

Tabanus bovinus Linnaeus, 1758 - Gólyás-berek: 1995.07.31., $10^{*}$ 9ᄋ, TS, +MAL - Ropolypuszta: 1980.08.06., 2O, CSM; 1980.08.07., $10^{\star} 1$ 1\%, TS.

Tabanus bromius Linnaeus, 1758 - Gólyás-berek: 1995.07.31., 7\%, TS, +MAL - Kardosfapuszta: 1985.08.14., 10 10 12Q, TS - Máriaasszony-sziget: 1996.06.11., 6O, TS - Ropolypuszta: 1980.08.06., 10 , CSM; 1980.08.06., $10^{\pi} 720$, TS, +MAL; 1980.08.07., 30^ 126ᄋ, TS, +MAL; 1982.06.27., 1Q, TS; 1985.08.14., 10 100, TS; 1988.05.30., 20, TS, +MAL; 1988.07.14., 1O, TS, +MAL

Tabanus cordiger Meigen, 1820 -

Kardosfapuszta: 1985.08.14., 1Q, TS.

Tabanus glaucopis Meigen, 1820 Kardosfapuszta: 1985.08.14., 10 , TS Ropolypuszta: 1980.08.06., 7O, CSM; 1985.08.14., $30^{\pi} 22$, TS; 1985.08.14., 112 @, TS (gépkocsiba repültek); 1988.08.01., 1O, TS, +MAL; 1988.08.14., 1 , $\mathrm{TS},+\mathrm{MAL}$

Tabanus maculicornis Zetterstedt, 1842 - Gólyás-berek: 1995.07.31., 6O, TS, +MAL - Máriaaszszony-sziget: 1996.06.11., 10 4O TS - Mély-éger: 1991.07.10., $10^{\pi}$ 7O, TS - Ropolypuszta: 1980.08.06., $10^{\star}$ 50, CSM; 1980.08.06., $10^{\star}$ 16o TS, +MAL; 1980.08.07., 6ᄋ, TS, +MAL.

Tabanus paradoxus Jaennicke, 1866 Ropolypuszta: 1985.08.14., 60, TS.

Tabanus spectabilis Loew, 1858 - Ropolypuszta: 1985.08.14., 2Q, TS.

Tabanus spodopterus Meigen, 1820 - Gólyás-berek: 1995.07.31., 2O, TS, +MAL - Ropolypuszta: 1980.08.07., $20^{\top}$ 6O, TS, +MAL.

Tabanus sudeticus Zeller, 1842 - Barcsi-Borókás (Barcs): 1984.07.31., $10^{\pi} 2$, TS - Homokpuszta: 1990.07.20., 1Q, NL - Ropolypuszta: 1980.08.06., $20^{\star} 17$,, CSM; 1980.08.06., $10^{\star} 10$, $\mathrm{TS}$; 1980.08.06., 2O, TS, +MAL.

Tabanus tergestinus Meigen, 1820 Kardosfapuszta: 1984.07.22., $\quad 1$, $\quad$ TS Ropolypuszta: 1980.08.06., 4O, CSM. 


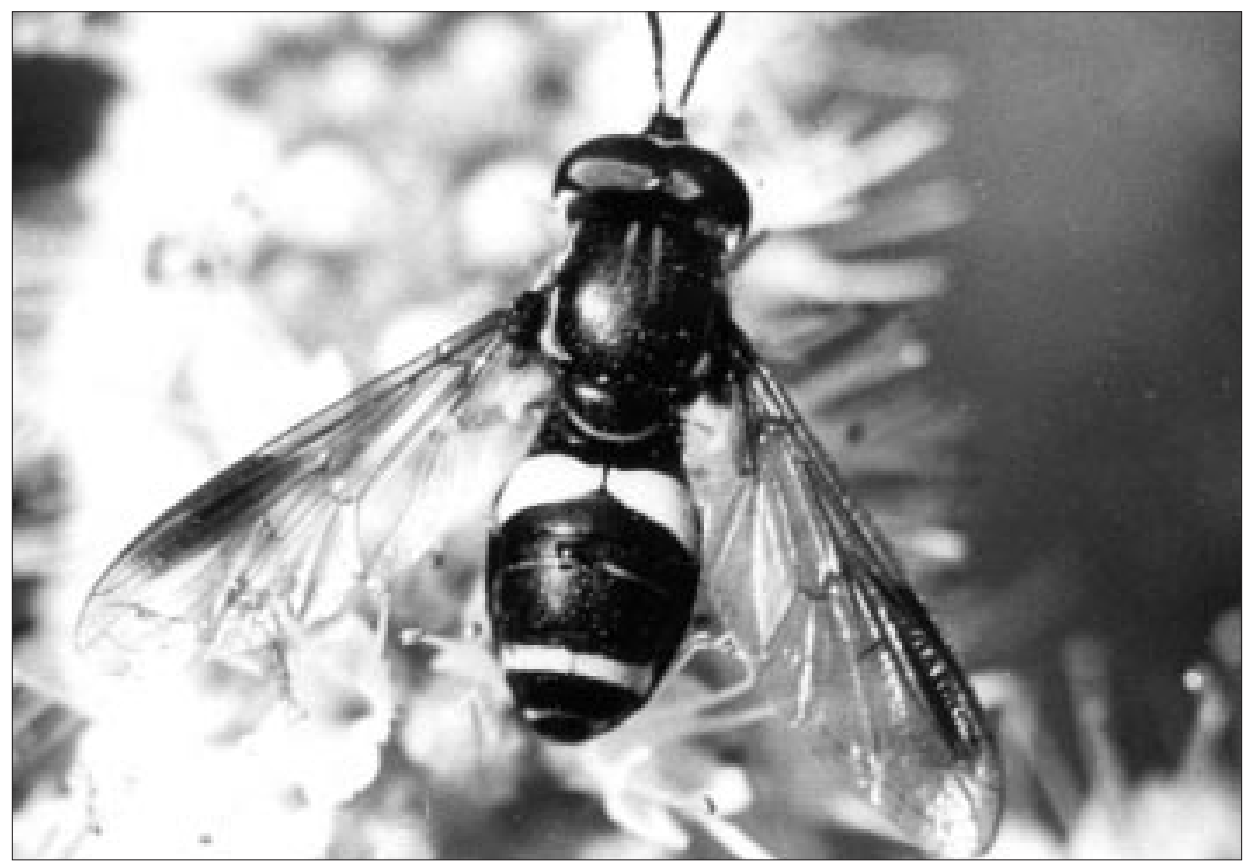

5. ábra: Chrysotoxum bicinctum (Syrphidae)

Therioplectes gigas (Herbst, 1787) - Farkaslakierdő: 1973.05.14., 1O, UÁ.

\section{Zengőlegyek (Syrphidae)}

A dolgozat 177 zengőlégy faj alapadatait tartalmazza.

Anasimyia contracta Claussen \& Torp, 1980 Cseberki-erdő: 1988.07.23., $10^{\star}$ 2Q, TS.

Anasimyia interpuncta (Harris, 1776) - Kis-Balaton: 1979.06.17., 10 $0^{\star}, \mathrm{CSM}$.

Anasimyia lineata (Fabricius, 1787) - Baláta-tó: 1994.06.29., 10 3o, TS; 1997.06.12., 1O, MJ - Barcsi-borókás (Barcs): 1975.04.16., $20^{\star} 5$ \%, TS, +MAL - Kis-Balaton: 1979.06.17., $20^{\star}$ 3Q, TS; 1986.07.15., 1Q, PL; 1988.08.11., 2O,, TS - Kúti-őrház: 1975.05.29., 2Q, TS, +MAL;1975.08.25., $20^{\star} 3$ \%, TS, +MAL

Anasimyia transfuga (Linnaeus, 1758) - Balátató: 1994.07.05., 10 4Q, TS - Boronka: 1990.07.03., 1Q, MJ, +MAL - Böhönye: 1987.06.29., 10 1O , TS, + MAL.

Baccha elongata (Fabricius, 1775) - Baláta-tó: 1994.06.29., 2O, TS - Boronka: 1990.07.31., 10, MJ, +MAL - Cseberki-erdő: 1988.07.23., 2O, TS Nagy-gyótai-erdő: 1992.04.15., 10, TS - Potony: 1977. 09.05., $20^{\star}$ 1O, TS - Siófok: 1969.07.29., 1Q,
TS.

Baccha obscuripennis Meigen, 1822 - Baláta-tó: 1994.06.29., $20^{*}$ 3o, TS; 1994.07.01., 10, TS, +MAL - Kis-Balaton: 1986.07.15., 1Q, PA; 1986.07.15., 1Q, PL.

Brachyopa bicolor (Fallén, 1817) Ropolypuszta: 1988.07.23., $10^{\star} 3$ \% , TS.

Brachyopa dorsata Zetterstedt, 1838 - Baláta-tó: 1994.06.29., 10" TS.

Brachypalpoides lentus (Meigen, 1822) - Barcsiborókás (Darány): 1975.05.17., 1O, TS, +MAL.

Callicera aenea (Fabricius, 1781) - Baláta-tó: 1994.07.05., 10, TS - Barcsi-borókás (Barcs): 1977. 05.02., 10 , TS - Csikota: 1977.05.02., $10^{\star} 1$ 10, TS.

Chalcosyrphus nemorum (Fabricius, 1805) Baláta-tó: 1994.06.29., 20, TS; 1994.07.01., 3Q, TS, +MAL - Erdősház-I.: 1987.07.01., 1@, TS, +MAL; 1987.07.22., $10^{\top} 1$ 1, TS, +MAL; 1988.05.25., 1O, TS, +MAL; 1988.07.08., 1@, TS, +MAL - Kúti-őrház: 1978.08.27., $20^{\star} 1$ 1Q, TS - Nagy-berek: 1978.08.29., $10^{\star} 1$ 1,$\quad$ TS - Szenttamási-irtás: 1988.07.23., $20^{\star}$ 1Q, TS - Töröcske: 1988.07.24., $10^{\pi} 30$, TS.

Cheilosia aerea Dufour, 1848 - Soponyaihalastó: 1991.07.31., 10 $0^{\star}$, TS.

Cheilosia albitarsis (Meigen, 1822) - Baláta-tó: 1994.06.29., $10^{\star}$ 3O, TS - Darány: 1977.07.15., $20^{\star}$ 
1Q, TS, +TÁL - Kardosfapuszta: 1986.05.09., 10, TS - Kishárságy: 1986.05.09., $30^{\star} 10$, TS - Lugierdő (Potony): 1977.05.03., 120 90, TS - Potony: 1973.05.09., 40 10 1977.05.03., $50^{\pi}$ 9Q, TS - Szenna: 1986.05.09., $50^{\star}$ 4 , TS.

Cheilosia antiqua (Meigen, 1822) - Nagy-gyótai-erdő: 1992.04.15., 10, TS - Potony: 1977.05.03., 1Q, KÁ; 1977.05.03., 10, TS.

Cheilosia barbata Loew, 1857 - Baláta-tó: 1994.07.05., 20 4O , TS - Nagybajom: 1989.07.03., 1ᄋ, MJ, +MAL - Ropolypuszta: 1988.06.06., 1@, TS, +MAL - Töröcske: 1988.07.24., 10¹ 10, TS.

Cheilosia carbonaria Egger, 1860 - Igal: 1984.07.23., 2Q, TS - Kis-Balaton: 1980.07.09., 10 , DÁ - Ropolypuszta: 1988.07.23., $10^{\star} 10$, TS Tóközpuszta: 1959.08.06., 1Q̣, SÁ.

Cheilosia chloris (Meigen, 1822) - Lipótfa: 1986.05.09., 10, TS - Nagy-gyótai-erdő: 1992. 04.15., $20^{\star}$ 2Q, TS - Potony: 1977.05.13., 1O, KÁ.

Cheilosia chrysocoma (Meigen, 1822) - Dennaierdészlak: 1988.05.03., 10 $0^{\star}$, TS.

Cheilosia cynocephala Loew, 1840 - Baláta-tó: 1994.07.01., 1Q, TS, +MAL - Kardosfapuszta: 1984.07.22., 1@, TS - Kis-gyótai-erdő: 1995.05.30., 1Q, TS - Ropolypuszta: 1980.08.06., 1Q, TS Tóközpuszta: 1959.08.05., 1Q̣, SÁ.

Cheilosia gigantea (Zetterstedt, 1838) Kardosfapuszta: 1984.07.22., 10, TS.

Cheilosia illustrata (Harris, 1780) - Cseberki-erdő: 1988.07.23., 10 , TS - Igal: 1984.07.23., 1O, TS - Ropolypuszta: 1988.07.23., 10 , TS.

Cheilosia impressa Loew, 1840 - Kúti-őrház: 1975.0715., $10^{\star}$ 2Q, TS - Potony: 1977.05.03., $20^{\star}$, KÁ; 1977.05.03., 10 10 1Q, TS - Ropolypuszta: 1985.08.14., 30 10 , TS; 1987.05.16., 20 2 , TS; 1988.05.17., 1O, TS, +MAL; 1988.05.19., 1O, TS, +MAL - Töröcske: 1988.07.24., 10, TS - Siófok: 1986.08.22., 10, SGY.

Cheilosia mutabilis (Fallén, 1817) - Baláta-tó: 1994.06.29., 2O, TS - Hosszúvíz: 1989.07.16., 10, MJ, +MAL - Igal: 1984.07.23., 10 , TS - Szenna: 1984.07.22., $30^{\top} 2 \mathrm{O}$, TS.

Cheilosia nigripes (Meigen, 1822) - Kishárságy: 1986.05.09., 0@, TS - Mély-égeri-halastó: 1991.06.21., 10 , TS - Szenna: 1986.05.09., 10 $0^{\star}$, TS. Cheilosia pagana (Meigen, 1822) - Böhönye: 1987.07.11., 1Q, TS, +MAL - Kis-Balaton: 1956.09.10., 1@, JT - Lugi-erdő (Potony): 1977.
09.05., 20 1우, TS - Vízvár: 1992.06.17., 1Q̣, TS.

Cheilosia proxima (Zetterstedt, 1843) Töröcske: 1988.07.24., 10 $0^{\star}$, TS.

Cheilosia ranunculi Doczkal, 2000 Felsőszentmárton: 1997.05.06., 40 12O, TS Kishárságy: 1986.05.09., 20 , TS - Lankóci-erdő: 1996.05.10., 20 , TS - Lugi-erdő (Tótújfalu): 1997.05.06., 40 , TS - Márcadópuszta: 1986.05.09., 10 $0^{\star}$, TS - Potony: 1973.05.09., 10 , TS; 1977.05.03., 50 $0^{\star}$, KÁ; 1977.05.03., 110 , TS - Ropolypuszta: 1980.05.29., 30 , CSM; 1985.05.29., 40 Szenna: 1986.05.09., $10^{\star}, \quad$ TS - Tótújfalu: 1997.05.06., $30^{\star} 2$, TS.

Cheilosia schnabli (Becker, 1894) - Bőszénfa: 1957.09.01., 1Q, GA - Ropolypuszta: 1980.05.29., $10^{\star}$, CSM; 1980.05.29., 20 $0^{*}$, TS (det. C. Claussen).

Cheilosia scutellata (Fallén, 1817) - Középrigóc (valamennyi gombából kelt): 1971.04.29., 140 13O, BM; 1971.05.11., $10^{\pi} 10$, BM; 1971.05.15., 30 30, BM; 1971.05.22., 1Q, BM; 1971.05.31., 10³ 30, BM - Ropolypuszta: 1985.08.14., 50 10, TS - Szenttamási-irtás: 1988.07.23., $10^{\star} 1$ 1, TS.

Cheilosia soror (Zetterstedt, 1843) Balatonlelle: 1962.08.16., 10 , MF - Barcsi-borókás (Darány): 1975.09.04., 10 , TI; 1982.08.31., 30 1\%, TS - Boronka: 1990.07.31., 1@, MJ, +MAL Palinai-erdő: 1992.06.17., 10 $0^{\top}$, TS - Ropolypuszta: 1980.08.06., 1Q, TS - Siófok: 1969.07.29., 30 10, TS. Cheilosia variabilis (Panzer, 1798) - Potony: 1977.05.03., 2Q, TS; 1977.05.08., $10^{\star} 2$ 2Q, KÁ Töröcske: 1988.07.24., 10 10, TS

Cheilosia vernalis (Fallén, 1817) - Kis-Balaton: 1988.08.11., 20, TS - Szenna: 1986.05.09., 10, TS. Cheilosia vicina (Zetterstedt, 1894) - Lugi-erdő (Potony): 1977.05.03., 10 $10^{\pi}, \quad$ TS - Potony: 1977.05.03., 1Q, KÁ; 1977.05.03., 10 10, TS.

Cheilosia vulpina (Meigen, 1822) Ropolypuszta: 1988.07.23., $10^{\star}$ 3o, TS - Siófok: 1969.07.29., $40^{\pi}, \quad$ TS - Soponyai-halastó: 1991.05.31., 10, TS.

Chrysogaster cemiteriorum (Linnaeus, 1758) Ropolypuszta: 1985.08.14., 1ㅇ, TS.

Chrysogaster solstitialis (Fallén, 1817) Csikota: 1975.07.15., $10^{\star}$ 4Q, TS - Kúti-őrház: 1975.07.15., 3O, TS - Ropolypuszta: 1985.08.14., 4 우, TS.

Chrysotoxum arcuatum (Linnaeus, 1758) - Erdősház-I.: 1988.06.02., 1@, TS, +MAL - Kúti-őrház: 1978.08.27., $10^{\star} 3$ o , TS - Nagy-berek: 1977.09.05., 
$10^{\star} 30$, TS; 1978.08.29., $10^{\star} 2 \mathrm{Q}, \mathrm{CSM} ; 1978.08 .29$. $20^{\pi} 1$, TS - Ropolypuszta: 1988.05.19., $10^{\star}$, TS, +MAL; 1988.06.02., 10 $0^{\star}$, TS, +MAL; 1988.08.26., 1Q, TS, +MAL - Tóközpuszta: 1959.08.06., 1O, SÁ. Chrysotoxum bicinctum (Linnaeus, 1758) Baláta-tó: 1989.06.23., 1O, MJ, +MAL; 1994.06.29., $20{ }^{\star} 1$ 1, TS - Barcsi-borókás (Darány): 1977.08.14., 1ㅇ, TS, +TÁL; 1986.08.11., 1ㅇ, TS - Böhönye: 1987.07.20., 1@, TS, +MAL - Kúti-őrház: 1975.07.15., $10^{\star} 3$ 3o, TS - Nagy-berek: 1978.08.29., $10^{\star} 2 \mathrm{O}, \mathrm{TS}-$ Potony: 1976.06.12., 20, TS Ropolypuszta: 1988.06.06., $10^{\star}$, TS, +MAL Szerenkei-erdő: 1988.07.23., $10^{\pi} 10$, TS.

Chrysotoxum cautum (Harris, 1776) - ErdősházI.: 1987.07.05., 10 10, TS, +MAL; 1987.07.25., 10 $0^{\star}$, TS, +MAL - Kishárságy: 1986.05.09., 20 , TS - Potony: 1977.05.03., 30 10, TS - Ropolypuszta: 1988.05.16., 10 $0^{\star}$, TS, +MAL; 1988.05.20., 10 $0^{\star}$, TS, +MAL - Szenna: 1986.05.09., 10 $0^{\star}$, TS.

Chrysotoxum vernale Loew, 1841 - Kishárságy: 1986.05.09., 1O, TS - Szenna: 1986.05.09., 3@, TS.

Chrysotoxum verralli Collin, 1940 - Baláta-tó: 1994.07.05., 10 , TS; 1997.06.12., 1@, MJ - Barcsiborókás: 1984.07.31., 3@, TS - Böhönye: 1987.07.07., $10^{\pi} 1 Q$, TS, +MAL - Csikota: 1975.07.15., $10^{\Uparrow}$ 3o, TS; 1978.08.29., 1O, TS - Erdősház-I.: 1987.07.31., 1O, TS, +MAL; 1988.07.12., $10^{\star} 1$, , TS, +MAL; 1988.07.18., 1ᄋ, TS, +MAL Hosszúvíz: 1989.07.15., $10^{\star}$ 1@, MJ, +MAL; 1989.07.17., 1Q, MJ, +MAL; 1989.07.24., 1Q, MJ +MAL - Kúti-őrház: 1978.08.27., 2Q, TS - Nagy-berek: 1978.08.29., $10^{\star} 2$ Q, TS.

Criorhina asilica (Fallén, 1816) Márcadópuszta: 1986.05.09., 10 $0^{\star}$, TS.

Criorhina berberina (Fabricius, 1805) - Dennaerdő: 1988.05.03., 2Q, TS - Potony: 1977.05.03., 1Q, TS. Criorhina ranunculi (Panzer, 1804) Ropolypuszta: 1980.05.29., 10 $0^{\star}$, TS.

Dasysyrphus albostriatus (Fallén, 1817) Baláta-tó: 1994.06.29., 10, TS - Csikota: 1984. 07.31., 10 $0^{\star}$, TS - Erdősház-I.: 1988. 05.30., $10^{\star}$ 10, PJ.

Dasysyrphus hilaris (Zetterstedt, 1843) - Nagyberek: 1977.05.02., 10, KÁ.

Dasysyrphus tricinctus (Fallén, 1817) - Szenttamási-irtás: 1988.07.23., 1Q, TS - Töröcske: 1988.07.24., 10, TS.

Dasysyrphus venustus (Meigen, 1822) - Csikota: 1977.05.02., 30 10, TS - Nagy-berek: 1977.05.02., 2Q, KÁ - Potony: 1977.05.03., 1@, KÁ; 1977.05.03., $10^{\pi} 30$, TS.

Didea alneti (Fallén, 1817) - Baláta-tó: 1994.07.05., 10, TS

Didea intermedia Loew, 1854 - Kúti-őrház: 1978.08.27., $20^{\star} 1$ 1 , TS - Nagy-berek: 1976.06.11., $10^{\pi} 2 \mathrm{Q}, \mathrm{TS}$.

Epistrophe eligans (Harris, 1780) Ropolypuszta: 1988.05.17., 10 $0^{\star}, \mathrm{TS},+\mathrm{MAL}$.

Epistrophe flava Doczkal \& Schmid, 1994 Nagy-gyótai-erdő: 1992.04.15., 10 $0^{*}$, TS.

Epistrophe grossulariae (Meigen, 1822) - Nagyberek: 1977.09.05., 2Q, TS - Szenttamási-irtás: 1988.07.23., 10, TS

Epistrophe melanostoma (Zetterstedt, 1843) Lankóci-erdő: 1993.04.28., 2Q, TS.

Epistrophe nitidicollis (Meigen, 1822) - Balátató: 1994.06.29., 2Q, TS - Csikota: 1977.05.02., 10 KÁ; 1977.05.02., 30 3 1Q, TS - Kaposvár: 1983.05.16., 10 10, VÉ, +FÉNY - Potony: 1977.05.03., 7@, KÁ; 1979.05.03., $20^{\pi}$ 1Q, TS Töröcske: 1988.07.24., 10, TS.

Episyrphus balteatus (De Geer, 1776) Balatonberény: 1985.08.19., 1Q, SGY; 1986.07.30., $10^{\star}$, SGY - Balatonfenyves: 1957.08.06., $90^{\star} 11$, ES; 1986.06.30., 10 10, SGY - Balatonföldvár: 1985.08.04., 1O, SGY - Balatonlelle: 1986.08.14., $10^{\top} 2 \mathrm{Q}, \mathrm{SGY}$ - Balatonszemes: 1957.06.18., 1Q, SÁ - Baláta-tó: 1989.06.29., $10^{\star}$ 30 , MJ, +MAL; 1994.06.29., 60 15\%, TS; 1994.07.01., $10^{\pi}$ 7o, TS, +MAL - Bankó-hegy: 1988.07.24., 30 60, TS Boronka: 1990.07.31., $20^{\star}$ 1O, MJ, +MAL Csikota: 1984.07.31., 70 40, TS - Enyezdi-rakodó: 1988.07.24., 20 40, TS - Erdősház-I.: 1987.08.28., 1O, TS, +MAL - Erdősház-I.: 1987.09.17., 10 10 10, TS, +MAL; 1987.10.02., $10^{\top} 10, \mathrm{TS},+\mathrm{MAL}$; 1987.10.27., 1Q, TS, +MAL; 1988.07.04., 1@, TS, +MAL; 1988.05.30., $30^{\star}$ 20, PJ - Hosszúvíz: 1989.07.15., 40 50, MJ, +MAL; 1989.07.16., 40 30, MJ, +MAL; 1989.07.17., 60 90, MJ, +MAL; 1989.07.18., $20^{\star}$ 4O, MJ, +MAL; 1989.07.19., $40^{\star}$ 2Q, MJ +MAL; 1988.07.21., $20^{\top} 30$, MJ, +MAL; 1989.07.22., 60 9Q, MJ, +MAL; 1989.07.23., $20^{\star}$ 1Q, MJ, +MAL; 1989.07.24., $10^{\star} 5$ \%, MJ +MAL; 1989.07.27., 30 2Q, MJ, +MAL; 1989.07.29., $10^{\pi}$ 2ᄋ, MJ +MAL; 1988.08.05., $10^{\star} 5$ \% , MJ, +MAL; 1989.08.07., 3Q, MJ, +MAL - Igal: 1984.07.23., 60 3O, TS - Kaposvár: 1964.08.16., 1O, A, +FÉNY; 1982.08.02., 10, VÉ - Kis-Balaton: 1979.06.17., 


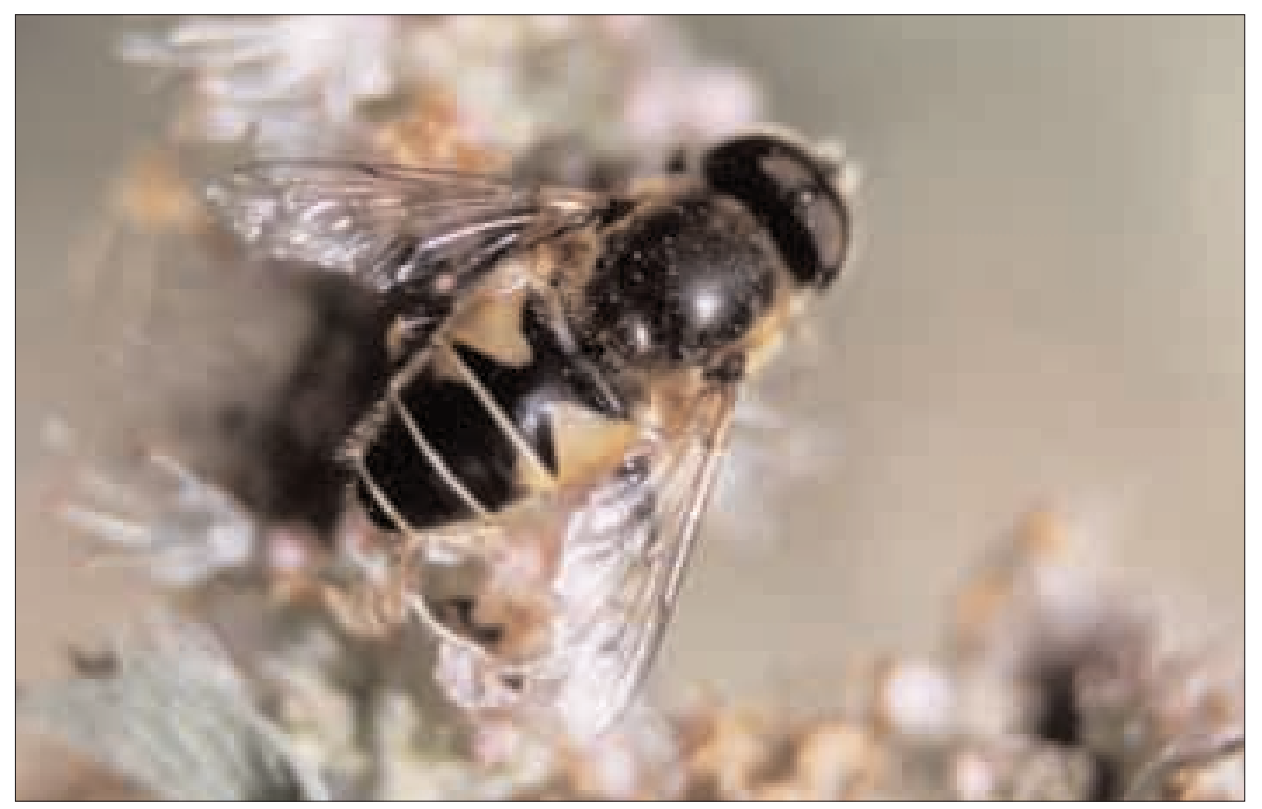

6. ábra: Eristalis arbustorum (Syrphidae)

10 , CSM - Kishárságy: 1986.05.09., 1O, TS - Kútiőrház: 1975.07.15., 40 1Q, TS; 1978.08.27., 50, CSM; 1978.08.27., $80^{\pi}$ 10, TS; 1982.08.31., $20^{\star} 30$, TS - Lengyeltóti: 1962.07.11., 10 , A, +FÉNY Nagybajom: 1989.07.03., $10^{\star} 10$, MJ, +MAL Nagy-berek: $1976.08 .05 ., \quad 140^{*} \quad 320, \quad \mathrm{TS}$; 1977.05.02., $10^{\star}$ 2O, KÁ; 1977.09.05., $30^{\pi}$ 2Q, TS; 1978.08.29., $20^{\star} 5$ \%, TS - Nyugati-berek: 1989.06.26., 30 5o, TS - Potony: 1976.06.12., 3o, TS; 1977.04.05., 20 1Q, TS; 1977.05.03., 10, KÁ; 1977.05.03., $10^{\star} 10$, TS; 1977.09.05., $10^{\star} 20$, TS Ropolypuszta: 1988.07.04., 1O, TS, +MAL; 1988.08.18., $10^{\star}$ 3Q, HA - Siófok: 1969.07.29., $10^{\pi}$ 1\%, TS - Somogytarnóca: 1984.07.30., 907 70, TS Zamárdi: 1957.07.01., 10 , SÁ.

Eristalinus aeneus (Scopoli, 1763) - Baláta-tó: 1994.06.29., 2Q, TS - Bélatelep: 1963.04.15., DÓ Hosszúvíz: 1989.07.22., 10 10, MJ, +MAL - KisBalaton: 1979.06.17., $10^{\pi}$ 10, CSM; 1979.06.17., 2Q, TS; 1988.08.11., 2O, TS - Kúti-őrház: 1975.07.15., 20 , TS; 1978.08.27., $20^{\star} 1$ 1Q, TS Nagy-berek: 1977.09.05., $10^{\star} 30$, TS; 1978.08.29., $10^{\star}$ 2Q, TS - Nagy-gyótai-erdő: 1992.04.15., 10, TS - Potony: 1977.05.03., 4Q, KÁ - Somogytarnóca: 1984.07.30., $20^{\star} 10$, TS.
Eristalinus sepulchralis (Linnaeus, 1758) Balatonföldvár: 1968.08.14., $10^{\star}$ 1Q, TS - Baláta-tó: 1994.07.01., $10^{\star}$ 60, TS, +MAL; 1994.07.05., 2ᄋ, TS - Barcsi-borókás (Darány): 1986.08.11., 10, TS - Hosszúvíz: 1989.07.16., 1Q, MJ, +MAL - Kis-Balaton: 1979.06.17., $20^{\star} 1$ 1 , CSM; 1979.06.17., 2ᄋ, TS; 1988.08.11., 3Q, TS - Kúti-őrház: 1975.07.15., $40^{\pi}$ 5\%, TS - Nagy-berek: 1977.09.05., $10^{\pi} 1$ Q, $\mathrm{TI}$; 1977.09.05., 90 4Q, TS; 1978.08.29., 2Q, TS Potony: 1977.05.03., 2Q, KÁ - Ropolypuszta: 1985.08.14., 10, TS.

Eoseristalis abusivus Collin, 1931 - Vörs: 1979.06.17., 10 $0^{\pi}$, TS.

Eristalis arbustorum (Linnaeus, 1758) Balatonfenyves: 1957.08.06., $380^{\star} \quad 60$, ES; 1984.09.01., $\quad 10^{\star}, \quad$ SGY - Balatonföldvár: 1968.08.14., $20^{\star}$ 4o, TS - Balatonlelle: 1962.08.16., $10^{\star}$ 2Q, MF - Baláta-tó: 1989.10.06., 30 2Q, TS; 1994.06.29., 160 50, TS; 1994.07.01., 2Q, TS, +MAL - Bankó-hegy: 1988.07.24., 60 110, TS Barcsi-borókás (Darány): 1986.08.11., 10 20, TS Csikota: 1984.07.31., 40³ 3Q, TS - Enyezdi-rakodó: 1988.07.24., 20 50, TS - Hosszúvíz: 1989.07.15., $20^{\star}, \mathrm{MJ},+\mathrm{MAL} ; 1989.07 .16 ., 80^{\star} 50$, MJ, +MAL; 
1989.07.17., $20^{\star}$ 1Q, MJ, +MAL; 1989.07.18., 1Q, MJ, +MAL; 1989.07.19., 2ᄋ, MJ +MAL; 1989.07.22., $20^{\star} 1$ 1Q, MJ, +MAL; 1988.07.21., $20^{\star}$, MJ, +MAL; 1989.07.23., $20^{*} 1$ 1 , MJ, +MAL; 1989.07.24., $10^{\pi}, \mathrm{MJ}+\mathrm{MAL} ; 1989.07 .27 ., 30^{\pi} 2 \mathrm{Q}$, MJ, +MAL; 1989.07.28., 50 1\%, MJ +MAL; 1989.07.30., 2O, MJ +MAL; 1989.08.01., 10 $0^{\star}$, MJ, +MAL; 1988.08.05., $10^{\star} \quad 1 \%, \quad \mathrm{MJ}, \quad+\mathrm{MAL}$; 1989.08.07., 10, MJ, +MAL; 1989.08.12., $20^{*} 10$, MJ, +MAL - Igal: 1984.07.23., 840 102Q, TS - Kaposvár: 1961.06.16., 1Q, BP - Kis-Balaton 1979.06.17., 20 , TS - Kúti-őrház: 1978.08.27., 10 2Q, TS; 1978.08.28., $10^{\star} 1$ 1Q, TS; 1984.07.30., $80^{\star}$ 30, TS - Nyugati-berek: 1989.06.26., $80^{\star} 30$, TS Potony: 1976.06.18., 1Q, TS; 1977.05.03., 30 30, KÁ; 1977.05.03., 40 8Q, TS - Siófok: 1969.07.29.,

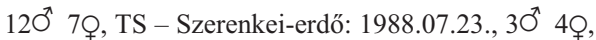
TS - Zamárdi: 1958.05.01., 20, KZ.

Eristalis horticola (De Geer, 1976) - Barcsi-borókás (Barcs): 1975.09.06., 30, TS, +MAL Csikota: 1984.07.31., $20^{\star}$ 1Q, TS - Darány: 1975.09.04., $10^{\star}$ 2Q, TI; 1975.09.04., $10^{\star} 3 Q$, TS Kúti-ôrház: $\quad 1978.08 .27 ., \quad 40^{\star} \quad 20, \quad$ TS Márcadópuszta: 1986.05.09., 1O, TS - Nagy-berek: 1977.09.05., $10^{\pi} 2 \mathrm{O}$, TI; 1978.08.29., 1O, TS Töröcske: 1988.07.24., 10 $0^{\star}$, TS

Eristalis interrupta (Poda, 1761) - Balatonlelle: 1962.08.16., 10 10, MF - Baláta-tó: 1994.06.29., $20^{\star}$ 1Q, TS - Bankó-hegy: 1988.07.24., $10^{\star} 3$ 3\%, TS - Barcsi-borókás (Darány): 1984.07.31., 1O, TS; 1986.08.11., 10 $0^{\star}$, TS - Darány: 1975.07.15., $70^{\star}$ 20, TS - Kerék-hegy: 1992.06.27., 20 , TS - Kúti-őrház: 1982.08.31., $20^{\star}$ 1O, TS - Nagy-berek: 1977.09.05., $10^{\top} 2 \mathrm{O}, \mathrm{TS} ; 1980.08 .29 ., 2 \mathrm{Q}, \mathrm{CSM}$ - Potony: 1973.05.03., 1Q, KÁ - Siófok: 1969.07.29., $10^{\star} 1$ 1, TS - Szenna: 1986.05.09., 10 , TS.

Eristalis intricarius (Linnaeus, 1758) - Cseberkierdő: 1988.07.23., 1ㅇ, TS.

Eristalis pertinax (Scopoli, 1763) - Baláta-tó: 1994.07.05., 2Q, TS - Bankó-hegy: 1988.07.24., $20^{\circ}$ 1Q, TS - Bőszénfa: 1957.09.01., 1Q, GA - Darány: 1975.07.15., 40 7Q, TS - Enyezdi-rakodó: 1988.07.24., 2Q, TS - Kúti-őrház: 1975.07.15., 40 3Q, TS; 1978.08.27., $20^{\Uparrow} 1$ 1Q, TS - Márcadópuszta: 1986.05.09., 2Q, TS - Nagy-berek: 1978.08.29., $10^{\star}$ 2Q, CSM - Potony: 1977.05.03., $10^{\pi} 30$, TS Szerenkei-erdő: 1988.07.23., 20, TS,

Eristalis pratorum (Meigen, 1822) - Barcsi-bo- rókás (Barcs): 1975.09.04., 10, TI - Darány: 1975.09.04., 1Q, TS - Nagy-berek: 1977.09.05., 10 TI - Ropolypuszta: 1988.07.23., $10^{\star} 1$ 1 , TS.

Eristalis rupium (Fabricius, 1805) - Soponyaihalastó: 1991.04.13., 20 , NL.

Eristalis tenax (Linnaeus, 1758) Balatonfenyves: 1957.08.06., $20^{\star}$, ES - Balatonkiliti: 1955.07.20., 1ㅇ, ML - Balatonőszöd: 1962.08.09., 10, MV - Baláta-tó: 1989.10.06., $120^{\star}$ 7Q, TS; 1994.06.29., 90 4우, TS; 1994.07.01., 40 20, TS, +MAL - Bankó-hegy: 1988.07.24., 80 4O, TS Barcsi-borókás (Darány):1986.08.11., 10 , TS Bélatelep: 1943.09.20., 1Q, MÉ - Csikota: 1984.07.31., 30 10, TS - Darány: 1975.07.15., $20^{\star}$ 5O, TS - Enyezdi-rakodó: 1988.07.24., 2O, TS - Erdősház-I.: 1988.05.30., $10^{\star}$ 1o, PJ - Hosszúvíz: 1989.07.15., 10 $0^{\star}, \mathrm{MJ},+\mathrm{MAL} ; 1989.07 .23 ., 20^{\star}, \mathrm{MJ}$, +MAL - Igal: 1984.07.23., 80 60, TS - Kaposvár: 1963.05.23., 1O, A, +FÉNY; 1964.07.15., 10 , A, +FÉNY; 1964.09.05., 10, A, +FÉNY; 1965.06.04., 1O, A, +FÉNY; 1965.07.25., 10 , A, +FÉNY - KisBalaton: 1979.06.17., 10 , TS - Kúti-őrház: 1975.07.15., 10 $0^{\star}$, TS; 1978.08.27., $20^{\star}$ 3o, CSM; 1982.08.31., 20 $0^{\text {* }}$, TS - Lengyeltóti: 1962.06.21., 10 $0^{\star}, \mathrm{A},+\mathrm{FÉNY}$ - Nagy-berek: 1977.09.05., $30^{\pi} 2 \mathrm{O}$, TS; 1977.09.05., 50 7Q, TI; 1979.08.29., $20^{\pi}$, TS Nyugati-berek: 1989.06.26., $10^{\pi} 20$, TS - Potony: 1977.05.03., 1Q, KÁ; 1977.05.03., 20 10 , TS; 1977.09.05., 10 $0^{\top}$, TS - Ropolypuszta: 1988.08.18., $10^{\pi}$ 2Q, HA - Siófok: 1969.07.29., 3Q, TS Somogytarnóca: 1984.07.30., 50 2Q, TS - Zamárdi: 1965.08.28., 1o, ML.

Eumerus grandis Meigen, 1822 - Barcsi-borókás (Barcs): 1975.07.15., 10 10, TS - Barcsi-borókás (Darány): 1977.05.02., 10 10, TS - Kúti-őrház: 1975.07.15., $10^{\star} 1$ Q, TS.

Eumerus ornatus Meigen, 1822 - Baláta-tó: 1994.07.05., 10 $0^{\pi}$, TS.

Eumerus ovatus Loew, 1848 - Darány: 1977.05.02., 10, TS.

Eumerus sabulonum (Fallén, 1817) - Csikota: 1977.07.16., 10 1O, TS, +TÁL - Barcsi-borókás (Barcs): 1975.08.25., 10, TS, +MAL.

Eumerus sogdianus Stackelberg, 1952 Balatonfenyves: 1957.08.06., 1\%, ES Ropolypuszta: 1988.07.23., 10 , TS.

Eumerus strigatus (Fallén, 1817) - Bankó-hegy: 1988.07.24., 10 , TS - Erdősház-I.: 1987.09.12., 10, TS, +MAL - Nagybajom: 1989.07.03., 1O, MJ, 
+MAL - Ropolypuszta: 1987.09.12., 10, TS, +MAL. Eumerus tricolor (Fabricius, 1798) Ropolypuszta: 1988.07.23., 1O, TS. Eumerus tuberculatus Rondani, 1857 Balatonfenyves: 1957.08.06., 10, ES. Eupeodes corollae (Fabricius, 1794) Balatonfenyves: 1986.06.30., 1\%, SGY Balatonkiliti: 1955.07.16., 10 $0^{*}$, ML - Baláta-tó: 1989.06.23., 30 1O, MJ, +MAL; 1994.07.01., 3ᄋ, TS, +MAL - Bankó-hegy: 1988.07.24., 30 1Q, TS - Boronka: 1990.07.03., 1Q, MJ, +MAL; 1990.07.31., $20^{\pi} 1$ 1Q, MJ, +MAL - Csikota: 1984.07.31., 20 50, TS - Enyezdi-rakodó: 1988.07.24., 2Q, TS - Erdősház-I.: 1987.08.08., 1@, TS, +MAL; 1987.09.20., 1\%, TS, +MAL; 1988.05.30., $10^{\star}$ 4Q, PJ; 1988.06.20., 1Q, TS, +MAL - Hosszúvíz: 1989.07.15., 30^ 4Q, MJ, + MAL; 1989.07.16., $50^{\star} \quad 9$ \%, MJ, +MAL; 1989.07.17., 80` 12Q, MJ, +MAL; 1989.07.18., $60^{\star}$ 8Q, MJ, +MAL; 1989.07.19., 1ᄋ, MJ +MAL; 1989.07.20., 20³ 3Q, MJ, +MAL; 1988.07.21., $10^{\pi}$ 3Q, MJ, +MAL; 1989.07.22., 170 24O, MJ, +MAL; 1989.07.23., 80 21 4Q, MJ +MAL; 1989.07.27., $10^{\top} 20$, MJ, +MAL; 1989.07.28., 70 4Q, MJ +MAL; 1989.07.29., $30^{\star}$ 5Q, MJ +MAL; 1989.07.30., 90 23Q, MJ +MAL; 1989.08.01., 30 9ᄋ, MJ, +MAL; 1988.08.05., $20^{\star}$ 3@, MJ, +MAL; 1989.08.12., 1ᄋ, MJ, +MAL; 1989.09.08., 1Q, MJ +MAL; 1991.08.06., $20^{\star} 5$ \%, MJ, +MAL - Igal: 1984.07.23., 40 2Q, TS - Kaposvár: 1966.06.27., 10 10, $\mathrm{A},+\mathrm{FÉNY}$ - Kis-Balaton: 1979.06.17., 1Q, MF - Kúti-őrház: 1975.07.15., $90^{\pi}$ 3Q, TS - Nagy-berek: 1976.08.05., 20 1978.08.29., 30, TS - Ropolypuszta: 1988.08.18., $10^{\pi} 3$, HA - Somogytarnóca: 1984.07.30., 120 4 , TS.

Eupeodes lapponicus (Zetterstedt, 1838) - Hoszszúvíz: 1991.08.06., 1Q, MJ, +MAL - Kishárságy: 1986.05.09., 10, TS.

Eupeodes latifasciatus (Macquart, 1829) Felsőkak: 1991.04.16., 1@, MJ, +MAL - Hosszúvíz: 1989.07.24., 1@, MJ +MAL - Szerenkei-erdő: 1988.07.23., 10 $0^{\top}$, TS.

Eupeodes latilunulatus (Collin, 1931) Soponyai-halastó: 1990.04.11., 10 $0^{\pi}$, TS.

Eupeodes luniger (Meigen, 1822) - Baláta-tó:

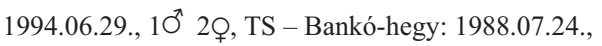
$10^{\star} 1$ 1, TS - Erdősház-I.: 1987.09.22., 1O, TS,
+MAL; 1987.09.27., 1Q, TS, +MAL - Hosszúvíz: 1989.07.30., 10 $0^{\star}$, MJ +MAL - Ropolypuszta: 1987.09.22., 1O, TS, +MAL - Somogytarnóca: 1984.07.30., $10^{\star}$, TS

Ferdinandea cuprea (Scopoli, 1763) - Baláta-tó: 1994.07.05., 1Q, TS - Barcsi-borókás (Darány): 1984.07.31., 1Q, TS - Hosszúvíz: 1989.07.23., 10 , MJ, +MAL; 1989.07.30., 10, MJ +MAL; 1991.08.06., 1Q, MJ, +MAL; 1988.08.16., $10^{\star}$, MJ, +MAL - Kúti-őrház: 1975.07.15., 1@, TS - Potony: 1977.05.03., 20 , KÁ; 1977.05.03., 30 10, TS - Zákány: 1982.06.24., 10, A.

Ferdinandea ruficornis (Fabricius, 1775) Baláta-tó: 1988.07.10., 1@, MJ; 1997.06.12., 1@, MJ - Lankóci-erdő: 1993.05.04., 1@, TS.

Helophilus hybridus Loew, 1846 - Barcsi-borókás (Darány): 1975.09.04., 10 10, TS - Kis-Balaton: 1979.06.17., 10, TS.

Helophilus pendulus (Linnaeus, 1758) Balatonfenyves: 1984.07.18., 1Q , SGY - Baláta-tó: 1989.10.06., $10^{\pi} 10$, TS; 1994.06.29., $10^{\star} 30$, TS Bankó-hegy: 1988.07.24., 2Q, TS - Barcsi-borókás (Barcs): 1975.09.04., 20 1Q, KÁ; 1975.09.05., 30 1ㅇ, TS - Barcsi-borókás (Drány): 1973.05.09., 50 2o, TS; 1975.04.28., 10, TS; 1975.04.30., 3o, TS; 1975.09.03., $10^{\star}$, TS; $1975.09 .04 ., 120^{\star} 30$, TI; 1975.09.04., 320 28Q, TS; $1975.09 .06 ., 320^{\pi} 21$ \%, TS, +MAL; 1975.09.08., 150 130, TS, +MAL; 1975.09.02., 150 4O, TS, +MAL; 1975.09.14., $120^{\star}$ 2ᄋ, TS, +MAL; 1975.09.16., 30 4Q, TS, +MAL; 1975.09.22., 1O, TS, +MAL; 1976.06.11., $20^{\star} 30$, TS; 1976.08.05., 20, TS - Hosszúvíz: 1989.07.18., $10^{\star}$, MJ, +MAL; 1989.07.22., $10^{\star}$, MJ, +MAL - Kúti-őrház: 1975.07.05., 2ᄋ, TS; 1975.07.15., 1우, TS; 1977.08.24., 270 23O, TS, +MAL - Nagy-berek: 1975.10.03., 70 3O, TS; 1976.09.13., 2O, TS; 1978.08.29., 40 5\%, TS - Tóközpuszta: 1959.07.06., 1Q̣, SÁ - Vörös-domb: 1987.05.15., $10^{\pi} 2 \mathrm{O}, \mathrm{TS}$

Helophilus trivittatus (Fabricius, 1805) Balatonföldvár: 1968.08.14., 20, TS - BarcsiBorókás (Darány): 1975.09.16., $10^{\Uparrow} 30$, TS, +MAL - Erdősház-I.: 1987.09.23., $10^{\star}$ 1Q, TS, +MAL Kis-Balaton: 1979.06.17., $10^{\star}$ 20, TS - Kúti-őrház: 1975.07.15., 30 50, TS - Nagy-berek: 1978.08.29., $10^{\star} 3 \mathrm{O}, \mathrm{TS}$.

Heringia heringi (Zetterstedt, 1843) - Baláta-tó: 1994.06.29., 10 1Q, TS - Hosszúvíz: 1989.07.16., 
1Q, MJ, +MAL; 1989.09.08., 1Q, MJ, +MAL - KisBalaton: 1986.07.15., $10^{\star}$, PA.

Heringia senilis Sack, 1938 - Soponyai-halastó: 1991.04.13., 10 $0^{\pi}$, TS.

Lejogaster tarsata (Megerle in Meigen, 1822) Baláta-tó: 1994.07.05., $10^{\pi} 2$ Q, TS - Csikota: 1975.04.28., $20^{\top}$, TS.

Lejops vittata (Meigen, 1822) - Kis-Balaton: 1979.06.17., 1Q, TS - Ropolypuszta: 1985.08.14., 1 , TS.

Melangyna compositarum (Verrall, 1873) Szerenkei-erdő: 1988.07.23., $10^{\star} 1$ 1\%, TS.

Melangyna lasiophthalma (Zetterstedt, 1843) Bélatelep: 1963.04.15., 1O, DÓ - Szentmihályhegy: 1997.04.02., $10^{\pi}$, TS.

Melanogaster nuda (Macquart, 1829) - Szenna: 1986.05.09., $20^{\pi}$ 20, TS.

Melanogaster aerosa (Loew, 1843)

Ropolypuszta: 1988.07.23., $20^{\star} 30$, TS.

Melanostoma mellinum (Linnaeus, 1758) -

Baláta-tó: 1994.07.01., $10^{\pi}$ 6O, TS, +MAL; 1994.07.05., $20^{\star}$ 6o, TS - Balatonberény: 1964.07.08., $10^{\pi}$ 1O, SÁ; 1984.07.18., 1O, SGY; 1984.07.30., $10^{\pi}$ 1O, SGY; 1985.08.09., 1O, SGY; 1985.08.19., 10, SGY; 1986.06.30., 10, SGY Balatonfenyves: 1957.08.06., 20, ES; 1984.08.15., 1O, SGY; 1984.09.01., 10 , SGY - Balatonföldvár: 1985.08.04., 1q, SGY; 1985.08.11., 1\%, SGY; 1986.09.08., 1Q, SGY - Balatonlelle: 1984.07.06., 10 $0^{\pi}$ SGY - Balatonszemes: 1957.06.18., 1O, SÁ Bankó-hegy: 1988.07.24., $10^{\pi}$ 4Q, TS - Barcs: 1978.07.04., 10 , PL - Barcsi-borókás (Barcs): 1975.10.03., 10 $0^{\pi}$, TS - Boronka: 1990.07.03., $10^{\pi}$ 1@, MJ, +MAL - Csikota: 1984.07.31., 30 4o, TS Csurgó: 1931.05.20., 1O, SZI - Enyezdi-rakodó: 1988.07.24., 2Q, TS - Erdősház-I.: 1987.06.30., 1Q TS, +MAL; 1987.08.09., $10^{\pi} 10$, TS, +MAL; 1987.08.11., 1\%, TS, +MAL; 1987.09.17., $10^{\pi} 1$, TS, +MAL; 1987.09.20., 10 $0^{\pi}, \quad$ TS, +MAL; 1987.09.23., 1\%, TS, +MAL; 1987.09.26., $10^{\star} 1 \%$, TS, +MAL; 1987.09.29., 1\%, TS, +MAL; 1987.10.04., 10 $0^{\pi}$, TS, +MAL; 1988.05.30., $10^{\star} 20$, PJ; 1988.06.07., 10, TS, +MAL; 1988.07.02., 1ᄋ, TS, +MAL - Hosszúvíz: 1988.08.17., 2O, MJ, +MAL; 1989.07.15., 2ᄋ, MJ, +MAL; 1989.07.16., $20^{\star}$ 4Q, MJ, +MAL; 1989.07.17., 50 4ᄋ, MJ, +MAL; 1989.07.18., $10^{\pi} 20, \quad \mathrm{MJ}, \quad+\mathrm{MAL}$; 1989.07.20., 2Q, MJ, +MAL; 1988.07.21., $10^{\star} 3$ \%,
MJ, +MAL; 1989.07.22., $30^{\star}$ 8O, MJ, +MAL; 1989.07.23., 5O, MJ, +MAL; 1989.07.24., $10^{\top}$ 4Q MJ +MAL; 1989.07.27., $10^{\pi} 20$, MJ, +MAL; 1989.07.28., $10^{\star}$ 3ᄋ, MJ +MAL; 1989.07.29., 4O, MJ +MAL; 1989.07.30., $10^{\star} 4$ Q, MJ +MAL; 1988.08.05., 2Q, MJ, +MAL; 1989.08.01., 3Q, MJ, +MAL; 1991.08.06., 1Q, MJ, +MAL; 1989.08.07., 1Q, MJ, +MAL; 1989.08.12., $10^{\star} 1$ 1\%, MJ, +MAL; 1988.08.16., $10^{\pi}$ 2ᄋ, MJ, +MAL - Igal: 1984.07.23., $20^{\pi}$ 3Q, TS - Kaposvár: 1963.09.27., 10, A, +FÉNY; 1965.08.20., 1Q, A, +FÉNY Kardosfapuszta: 1984.07.22., $20^{\star}$ 60, TS - Kis-Balaton: 1956.09.10., 4Q, JT; 1964.07.08., $20^{\star}$ 1\%, SÁ; 1979.06.17., 1Q, TS; 1980.07.09., 30, DÁ - Kútiőrház: 1975.07.15., $30^{\star}$ 6ᄋ, TS; 1982.08.31., $10^{\star}$ 4Q, TS - Nagy-berek: 1975.07.15., $10^{\pi} 3$ Q, TS; 1976.08.05., 5O, TS - Potony: 1973.05.09., $20^{\star}$, TS; 1977.05.03., $10^{\pi} 1$, $\mathrm{TS}$ - Ropolypuszta: 1985.08.14., 1O, TS; 1987.09.26., $10^{\star}$, TS, +MAL; 1988.08.18., $10^{\star} 1$ 1 , HA - Siófok: 1969.07.29., $40^{\star}$ 1Q, TS; 1984.08.12., 1Q, SGY - Somogytarnóca: 1984.07.30., 30 60, TS - Vörs: 1985.07.17., NM Zamárdi: 1965.07.09., 2Q, SÁ.

Melanostoma scalare (Fabricius, 1794) Balatonszemes: 1957.06.18., 1Q, SÁ - Baláta-tó: 1994.06.29., 7Q, TS - Barcsi-borókás (Darány): 1984.07.31., 1O, TS; 1984.08.11., 1Ơ, TS - Erdősház-I.: 1988.06.23., 1Q, TS, +MAL - Kerék-hegy: 1992.06.07., 30 70, TS - Nagy-berek: 1975.07.15., 3o, TS; 1976.08.05., $20^{\star}$ 12Q, TS - Nagy-gyótaierdő: 1992.04.15., 10 $0^{\star}$, TS - Potony: 1973.05.09., $10^{\pi} 4$, TS; 1977.09.05., $10^{\pi} 9$ \%, TS Ropolypuszta: 1985.08.14., 10, TS.

Meligramma cincta (Fallén, 1817) Balatonlelle: 1955.06.19., 30 , SÁ - Baláta-tó: 1994.06.29., 20, TS.

Meligramma guttata (Fallén, 1817) - Szerenkeierdő: 1988.07.23., 10 $0^{\star}$, TS.

Meliscaeva auricollis (Meigen, 1822) - Igal: 1984.07.23., 10 , TS - Cseberki-erdő: 1988.07.23., $10^{\pi}, \mathrm{TS}$.

Meliscaeva cinctella (Zetterstedt, 1843) Balatonlelle: 1955.06.19., 30, SÁ - Cseberki-erdő: 1988.07.23., $10^{\pi} 10$, TS.

Merodon avidus (Rossi, 1790) - Baláta-tó: 1994.06.29., 20 , TS - Barcsi-borókás (Darány): 1975.06.21., 1O, TS, +MAL; 1975.06.29., 2Q, TS, +MAL; 1975.07.15., 10 $0^{\pi}$, TS; 1975.08.25., 10 $10^{\pi}$, TS, 
+MAL; 1976.06.11., 40 , TS; 1979.08.08., 30 , CSM; 1984.07.31., 10 $0^{\star}$, TS - Csikota: 1984.07.31., 10 $10^{\star}$, TS. Merodon constans (Rossi, 1794) - Baláta-tó: 1994.07.05., 1@, TS - Hosszúvíz: 1989.07.23., 1Q, MJ, +MAL - Siófok: 1969.07.28., 20, TS.

Merodon equestris (Fabricius, 1794) Szerenkei-erdő: 1988.07.23., $10^{\star} 20$, TS.

Merodon nigritarsis Rondani, 1845 - Szenttamási-irtás: 1988.07.23., $30^{\star} 1$ 1, TS - Töröcske: 1988.07.24., 20, TS.

Merodon rufus Meigen, 1838 - Ropolypuszta: 1988.07.23., 10 , TS

Mesembrius peregrinus (Loew, 1846) - Balátató: 1994.06.29., 20, TS - Hosszúvíz: 1989.07.30., 1O, MJ +MAL; 1989.09.08., 19, MJ +MAL.

Microdon devius (Linnaeus, 1761) - Baláta-tó: 1994.06.29., 1o, TS.

Microdon eggeri Mik, 1897 - Kishárságy: 1986.05.09., 10 $0^{\star}$, TS - Potony: 1976.06.12., 10 $0^{\star}$, TS

Microdon mutabilis (Linnaeus, 1758) - Lugierdő (Potony): 1976.06.12., $10^{\star}$ 20, TS - Potony: 1976.06.12., $10^{\pi} 10, \mathrm{TS}$.

Myathropa florea (Linnaeus, 1758) Balatonfenyves: 1957.08.16., 10 Balatonföldvár: 1968.08.14., 10 , TS - Balatonlelle: 1962.08.16., 10 , MF - Balatonőszöd: 1962.08.09., 10, MV - Balatonszemes: 1962.08.06., 10 , MV Baláta-tó: 1994.07.05., 3o, TS - Barcsi-borókás (Barcs): 1978.08.27., 10 10, TS - Barcsi-borókás (Darány): 1986.08.11., 1Q, TS - Csikota: 1978.08.27., 3O, TS - Kúti-őrház: 1975.07.15., 10, TS - 1978.08.27., 10 40, CSM - Nagy-berek: 1975.09.05., 20 $0^{\top}$, TS; 1978.08.29., 1Q, CSM; 1978.08.29., $10^{\Uparrow}$ 2O, TS - Potony: 1977.05.03., 1Q, KÁ - Siófok: 1969.07.29., 30, TS. Myolepta dubia (Fabricius, 1805) Ropolypuszta: 1985.08.14., $10^{\star} 1$ 1 , TS.

Myolepta vara (Panzer, 1798) - Baláta-tó: 1994.06.29., 1O,, TS-Márcadópuszta: 1986.05.09., 10 , TS. Neoascia annexa (Müller, 1776) Balatonberény: 1985.07.03., 10 $0^{\star}$, TS - Baláta-tó: 1994.07.05., $20^{\star}$ 7Q, TS.

Neoascia geniculata (Meigen, 1822) - Nyugatiberek: 1989.06.26., 30, TS - Szerenkei-erdő: 1988.07.23., 10, TS.

Neoascia interrupta (Meigen, 1822) - Nagy-gyótai-erdő: 1992.04.15., $10^{\star} 2$ 2Q, TS - Töröcske: 1988.07.24., $20^{\star} 30$, TS.

Neoascia meticulosa (Scopoli, 1763) - Csurgós- kúti-völgy: 1987.05.15., 1Q, TS - Kis-Balaton: 1979.06.17., 1O, MF; 1980.07.09., 20 2O DÁ Potony: 1977.05.03., 1Q, TS - Szerenkei-erdő: 1988.07.23., $10^{\pi} 4$ ㅇ, TS.

Neoascia obliqua Coe, 1940 - Baláta-tó: 1994.06.29., $10^{\star}$ 6O, TS - Böhönye: 1987.06.24., 10 , TS, +MAL.

Neoascia podagrica (Fabricius, 1775) - Balátató: 1994.06.29., 4Q, TS - Hosszúvíz: 1989.07.22., 10 , MJ, +MAL; 1989.08.12., $10^{\star} 30$, MJ, +MAL.

Neoascia tenur (Harris, 1780) - Balatonberény: 1985.07.03., $20^{\star} 1$ 1Q, SGY - Kis-Balaton: 1964.07.08., 2Q, SÁ; 1985.07.31., 10 $0^{\star}$, VT; 1986.07.15., 10 $0^{\star}$, PA; 1986.07.15., 50 40, PL Nagy-gyótai-erdő: 1992.04.15., $20^{\star} 20$, TS.

Neocnemodon pubescens (Delucchi \& PschornWalcher, 1955) - Cseberki-erdő: 1988.07.23., 10, TS. Neocnemodon vitripennis (Meigen, 1822) Baláta-tó: 1994.07.05., 10 , TS - Szenttamási-irtás: 1988.07.23., 10', TS.

Orthonevra geniculata (Meigen, 1830) Szerenkei-erdő: 1988.07.23., 20 ${ }^{\star}$, TS.

Orthonevra nobilis (Fallén, 1817) - Cseberki-erdő: 1988.07.23., 10 1o, TS - Siófok: 1969.07.29., $10^{\pi}$, TS.

Orthonevra splendens (Meigen, 1822) - Balátató: 1994.06.29., $10^{\star} 1$ 1Q, TS

Paragus bicolor (Fabricius, 1794) - Barcsi-borókás (Barcs): 1975.09.05., 10, TS - Csikota: 197505. 09., 10, TS - Szerenkei-erdő: 1988.07.23., 10, TS. Paragus finitimus Goeldlin de Tiefenau, 1971 Ropolypuszta: 1988.07.23., 10, TS.

Paragus haemorrhous Meigen, 1822 Balatonberény: 1984.07.30., 10 , SGY Balatonfenyves: 1957.08.12., 1Q, ES - Boronka: 1990.07.31., $10^{\pi} 1$ 1, MJ, +MAL - Kúti-őrház: 1975.07.15., 10 $0^{\star}$, TS - Nagybajom: 1989.07.03., $10^{\star}$ 1Q, MJ, +MAL - Ropolypuszta: 1988.07.23., 10 4o, TS.

Paragus majoranae Rondani, 1857 - Baláta-tó: 1989.10.06., 10 $0^{\star}, \mathrm{TS} ; 1994.06 .29 ., 10^{\star} 3 \mathrm{O}, \mathrm{TS}$; 1994.07.01., 10 4O, TS, +MAL; 1998.06.10.,1, MJ - Boronka: 1990.07.31., 2Q, MJ, +MAL Ropolypuszta: 1988.05.29., 10 , TS, +MAL.

Parasyrphus lineola (Zetterstedt, 1843) - Balátató: 1994.07.05., 2Q, TS

Parasyrphus vittiger (Zetterstedt, 1843) - Balátató: 1994.06.29., 10 2O TS.

Parhelophilus frutetorum (Fabricius, 1775) - 
Ropolypuszta: 1988.07.23., 10 , TS

Parhelophilus versicolor (Fabricius, 1794) Balatonföldvár: $1968.08 .14 ., \quad 20^{\star} \quad 10$, TS; 1968.08.16., 1Q, TS - Balatonlelle: 1962.08.16., 1Q,

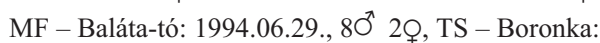
1990.07.03., 1Q, MJ, +MAL - Erdősház-I.: 1987.07.12., 1Q, TS, +MAL; 1988.07.10., 10, TS, +MAL - Hosszúvíz: 1989.07.19., 10, MJ +MAL; 1988.07.21., $10^{\star}$ 3Q, MJ, +MAL; 1988.08.16., 1O, MJ, +MAL - Kis-Balaton: 1979.06.17., $10^{\star} 30$, CSM; 1979.06.17., 150 11\%, TS; 1988.08.11., $10^{\star}$ 2ᄋ, TS - Nagy-berek: 1977.09.05., 2Q, TS.

Pipiza bimaculata Meigen, 1822 - Hosszúvíz: 1989.07.22., 1Q, MJ, +MAL.

Pipiza fasciata (Meigen, 1822) Balatonfenyves: 1957.08.02., 20 , ES.

Pipiza festiva Meigen, 1822 . Balatonfenyves:1957.08.10., 2Q, ES - Baláta-tó: 1994.07.01., 10 $0^{\star}$, TS, +MAL.

Pipiza noctiluca (Linnaeus, 1758) - Baláta-tó: 1994.07.05., $20^{\star}$ 1Q, TS - Dennai-erdészlak: 1988.05.03., 2Q, TS - Hosszúvíz: 1989.07.16., 1Q, MJ, +MAL; 1989.07.22., 1@, MJ, +MAL - Nagybajom: 1989.07.03., 1Q, MJ, +MAL - Potony: 1977.05.03., 20 , KÁ.

Pipizella divicoi (Goeldlin de Tiefenau, 1974) Enyezdi-rakodó: 1988.07.24., 20, TS.

Pipizella maculipennis (Meigen, 1822) - Potony: 1977.05.03., 10 $0^{\pi}$, TS.

Pipizella viduata (Linnaeus, 1758) Balatonberény: 1986.06.30., 10, SGY Balatonföldvár: 1968.08.14., 10 $0^{\star}$, TS; 1986.09.08., 1\%, SGY -Balatonfenyves: 1957.08.06., $80^{\star} 10$, ES; 1986.08.11., 10 ${ }^{\pi}$, SGY - Balatonlelle: 1986.08.14., 10, SGY - Balatonszemes: 1957.06.18., $20^{\star}$ 1Q, SÁ - Baláta-tó: 1994.06.29., 30` 1O, TS; 1994.07.01., $70^{\star}$ 2O, TS, +MAL - Bankó-hegy: 1988.07.24., 60 2Q, TS - Barcsi-borókás (Darány): 1975.09.04., 1\%, TS -Boronka: 1990.07.31., 10 $0^{\star}, \mathrm{MJ},+\mathrm{MAL}-$ Böhönye: 1987.07.07., 10 $0^{\star}$, TS, +MAL - Csikota: 1977.05.02., 10 20, TS - Erdősház-I.: 1987.07.30., $10^{\star}$, TS, +MAL; 1987.08.15., $10^{\star} 1 \mathrm{Q}$, TS, +MAL Hosszúvíz: 1989.07.22., $20^{\star}$ 1@, MJ, +MAL - Igal: 1984.07.23., 30 10, TS - Kishárságy: 1986.05.09., 20 , TS - Lipótfa: 1986.05.09., 10, TS - Lugi-erdő (Potony): 1977.05.03., 20 30, TS - Marcali: 1956.06.13., 10 $0^{\star}$, JT - Nagy-berek: 1977.05.02., $10^{\star}$ 1Q, TS - Potony: 1977.05.03., 2Q, KÁ; 1977.05.03., $10^{\star} 1 \mathrm{Q}, \mathrm{TS}$ - Ropolypuszta: 1985.07.14., $10^{\star}$, TS;
1988.05.19., $10^{\star}$, TS, +MAL; 1988.05.16., 10 $10^{\star}$, TS, +MAL; 1988.05.26., 10 $0^{\star}$, TS, +MAL; 1988.05.29., $10^{\star} 1$ \%, TS, +MAL; 1988.05.30., 10 $0^{\star}$, TS, +MAL; 1988.05.31., 10 $0^{\star}$, TS, +MAL; 1988.06.06., $10^{\star}$ 4Q TS, +MAL - Siófok: 1984.07.06., 20 , SGY - Vörs: 1985.07.17., 10 $10^{\star}, \mathrm{NM}$.

Pipizella virens (Fabricius, 1805) Kardosfapuszta: 1984.07.22., $20^{\star}$, TS.

Platycheirus angustatus (Zetterstedt, 1843) Baláta-tó: 1994.06.29., 2Q, TS - Barcsi-borókás (Barcs): 1979.07.08., $20^{\pi}$ 4ㅇ, CSM - Enyezdirakodó: 1988.07.24., $10^{\star}$ 1Q, TS - Hosszúvíz: 1989.07.18., 1O, MJ, +MAL; 1989.07.20., 1O, MJ, +MAL; 1988.08.05., 1Q, MJ, +MAL; 1989.08.12., $10^{\star} 1$ 1, MJ, +MAL - Kis-Balaton: 1980.07.09., 10 DÁ - Ropolypuszta: 1988.08.18., 1Q, HA - Zamárdi: 1955.06.19., 10, SÁ.

Platycheirus clypeatus (Meigen, 1822) - Balátató: 1994.07.01., 20 70, TS, +MAL - 1994.07.05., $10^{\pi} 30$, TS - Bankó-hegy: 1988.07.24., 3Q , TS Boronka: 1990.07.03., 10 $0^{\pi}$, MJ, +MAL - Csikota: 1975.07.15., 80 30, TS - Erdősház-I.: 1988.05.30., 2Q, PJ - Hosszúvíz: 1989.07.28., 1Q, MJ +MAL; 1989.07.22., $10^{\star}$ 1Q, MJ, +MAL - Igal: 1984.07.23., $10^{\pi}$ 2Q, TS - Kis-Balaton: 1979.06.17., 1O, CSM; 1980.07.09., 2Q, DÁ; 1986.07.15., 10 , PA - Nagyberek: 1976.08.05., $10^{\top}$ 2O, TS - Siófok: 1969. 07.29., 10 , TS - Zamárdi: 1980.07.27., 1Q, SÁ.

Platycheirus albimaus (Fabricius, 1781) Baláta-tó: 1989.06.29., 2O, MJ, +MAL - Kis-Balaton: 1985.07.17., 10 , NM - Lugi-erdő (Tótújfalu): 1977.05.03., 10, TS.

Platycheirus fulviventris (Macquart, 1829) Balatonfenyves: 1984.09.01., 1Q, SGY - Baláta-tó: 1994.07.01., 10² 2Q, TS, +MAL - Barcsi-borókás (Darány): 1984.07.31., 1, TS - Böhönye: 1987.07.10., 1Q, TS, +MAL - Kaposvár: 1963.09.27., 1Q, A, +FÉNY - Kis-Balaton: 1956.09.10., 10, JT; 1980.07.09., 1O, DÁ; 1986.07.15., 2Q, PA; 1986.07.15., 2Q, PL.

Platycheirus peltatus (Meigen, 1822) - Hosszúvíz: 1989.09.08., 1Q, MJ +MAL - Nagybajom:

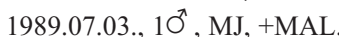

Platycheirus scutatus (Meigen, 1822) - Hosszúvíz: 1989.07.29., 1Q, MJ +MAL - Enyezdi-rakodó: 1988.07.24., 1Q, TS - Ropolypuszta: 1988.06.06., 10 , TS, +MAL.

Pyrophaena rosarum (Fabricius, 1787) - 
Enyezdi-rakodó: 1988.07.24., $10^{\star} 30$, TS - Kis-Balaton: 1980.07.05., $20^{\star}$ 1O, DÁ - Kúti-őrház: 1978.08.27., 30 10, TS - Nagy-berek: 1977.09.05., $10^{\pi} 30$, TS - Potony: 1976.06.12., $10^{\pi}$, TS Ropolypuszta: 1988.07.23., 1@, TS.

Rhingia campestris Meigen, 1822 - Potony: 1973.05.09., $20^{\star}$ 5O, TS; 1977.05.03., $40^{\star}$ 2Q, KÁ; 1977.05.03., $50^{\star} 8$ 8. TS; $1977.09 .05 ., 10^{\star} 1$ 1, TS Szerenkei-erdő: 1988.07.23., 30 10, TS - Töröcske: 1988.07.24., 3o, TS.

Scaeva pyrastri (Linnaeus, 1758) Balatonfenyves: 1957.08.06., $10^{\pi} 100$, ES Balatonföldvár: 1968.04.14., 2Q, TS - Baláta-tó: 1994.06.29., $20^{\star} 1$ 1Q, TS - Bankó-hegy: 1988.07.24., $20^{\star} 3$ 3o, TS - Csikota: 1984.07.31., $20^{\star} \mathrm{1} 1$, TS Hosszúvíz: 1989.07.17., 1Q, MJ, +MAL; 1989.07.18., 1@, MJ, +MAL; 1989.07.20., 1O, MJ, +MAL; 1989.07.29., 10, MJ +MAL; 1989.08.01., 1O, MJ, +MAL - Igal: 1984.07.23., $10^{\star} 2$ 2Q, TS Kúti-őrház: 1975.07.15.,40 50, TS - Ropolypuszta: 1985.08.14., $10^{\pi}$ 2Q, TS - Somogytarnóca: 1984. 07.30., $20^{\star}$ 1Q, TS - Zamárdi: 1957.08.15., 1O, KZ.

Scaeva selenitica (Meigen, 1822) - Baláta-tó: 1994.07.01., 1@, TS, +MAL; 1997.06.12., 20 , MJ; 1997.06.12., 20 $0^{\star}$, MJ, +MAL - Bankó-hegy: 1988.07.24., 1ㅇ, TS - Erdősház-I.: 1988.06.12., 10, TS, +MAL - Kúti-őrház: 1975.07.15., 30 1O, TS Nagy-berek: 1977.05.02., 2O, KÁ - Potony: 1976.06.12., 2o, TS.

Sphaerophoria batava Goeldlin de Tiefenau, 1974 - Barcs: 1978.07.04., 10 , PL - Barcsi-borókás (Darány): 1975.04.28., 20 , TS; 1975.09.04., 10 TI; 1977.05.02., 10 $0^{*}$, TS; 1978.08.27., 10 $0^{*}$, TS; 1982.08.31., 30 , TS; 1986.08.11., 20 20, TS - Kútiőrház: 1982.08.31., $80^{\pi}$ 30, TS - Ropolypuszta: 1980.08.06., 10 $0^{\pi}$, TS.

Sphaerophoria interrupta (Fabricius, 1805) Nagy-gyótai-erdő: 1992.04.15., 40, TS.

Sphaerophoria rueppellii (Wiedemann, 1830) Hosszúvíz: 1989.07.16., 1Q, MJ, +MAL; 1989.07.20., 10, MJ, +MAL; 1988.07.21., $10^{\pi} 1$ \%, MJ, +MAL; 1989.07.22., 1@, MJ, +MAL; 1989.07. 30., 2Q, MJ +MAL; 1988.08.05., 10, MJ, +MAL. Sphaerophoria scripta (Linnaeus, 1758) Balatonberény: 1964.07.08., 2Q, SÁ; 1984.07.03., $10^{\pi}$, SGY; 1984.08.12., $10^{\pi} 1$ 1 , SGY; 1986.06.30., 1Q, SGY - Balatonboglár: 1986.07.04., $10^{\star}$ 2Q, SGY; 1986.08.11., 1\%, SGY - Balatonfenyves:
1957.08.06., $90^{\star} 11$ Q, $\mathrm{ES} ; 1986.06 .30 ., 30^{\star} 50$, SGY; 1986.07.30., 10, SGY; 1986.08.11., 1Q, SGY Balatonföldvár: 1968.08.14., $10^{\star} \quad 30, \quad \mathrm{TS}$; 1985.08.04., 1O, SGY; 1986.07.22., 10, SGY; 1986.08.11., 10, SGY - Balatonlelle: 1955.06.19., 30 10, SÁ; 1984.07.06., $10^{\pi}$ 5ơ, SGY; 1984.07.15., $10^{\pi} 1$ 1 , SGY; 1984.08.12., 10, SGY; 1986.08.14., 20, SGY - Balatonőszöd: 1961.08.03., 1Q, MV; 1962.08.09., 2Q, MV; 1962.08.20., 10 $0^{\star}$, MV Balatonszemes: 1957.06.18., 1Q, SÁ; 1962.08.06., $10^{\pi} 10$, MV - Baláta-tó: 1989.06.29., 1Q, MJ, +MAL; 1989.10.06., $20^{\star} 5$ o, TS; 1994.06.29., 60 9ᄋ, TS; 1994.07.01., 10 60, TS, +MAL - Bankóhegy: 1988.07.24., 20 60, TS - Barcsi-borókás (Darány):1986.08.11., 10, TS - Boronka: 1990.07.03., $20^{\star}$ 1Q, MJ, +MAL; 1990.07.31., $10^{\star}$ 1ㅇ, MJ, +MAL - Böhönye: 1987.07.11., $10^{\pi} 1$ 1 , TS, +MAL - Csikota: 1984.07.31., 50 1@, TS - Erdősház-I.: 1988.05.31., 1@, TS, +MAL; 1987.07.12., 1\%, TS, +MAL; 1987.07.22., $10^{\star} 10$, TS, +MAL; 1987.07.23., $10^{\pi} 10, \mathrm{TS},+\mathrm{MAL} ; 1987.08 .05 ., 10^{\pi}$ 1Q, TS, +MAL; 1987.08.09., 1Q, TS, +MAL; 1987.09.08., 2O, TS, +MAL; 1987.09.11., 1@, TS, +MAL; 1987.09.19., 2Q, TS, +MAL; 1987.09.20., 1ᄋ, TS, +MAL; 1987.10.11., 1Q, TS, +MAL; 1988.05.24., 1O, TS, +MAL; 1988.05.30., 3Q, PJ; 1988.05.30., 1@, TS, +MAL; 1988.05.31., 1@, TS, +MAL - Felsőkak: 1991.04.16., 1@, MJ, +MAL Hosszúvíz: 1988.08.17., 4O, MJ, +MAL; 1989.07.15., $20^{\star}$ 4O, MJ, +MAL; 1989.07.16., 60 8Q, MJ, +MAL; 1989.07.17., 250 19ᄋ, MJ, +MAL; 1989.07.18., 110 23Q, MJ, +MAL; 1989.07.19., 3Q, MJ +MAL; 1989.07.20., 30 4\%, MJ, +MAL;

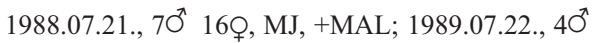
12O, MJ, +MAL; 1989.07.23., 50 12O, MJ, +MAL; 1989.07.24., $80^{\star}$ 6O, MJ +MAL; 1989.07.27., 140 21O, MJ, +MAL; 1989.07.28., $20^{\top}$ 4O, MJ +MAL; 1989.07.29., $10^{\top} 2$ Q, MJ +MAL; 1989.07.30., $160^{\star}$ 23O, MJ +MAL; 1989.08.01., 50 60, MJ, +MAL; 1988.08.05., 50 9ᄋ, MJ, +MAL; 1989.08.07., 30 7O, MJ, +MAL; 1989.08.12., 50 30, MJ, +MAL; 1989.09.08., $10^{\star} 1 Q$, MJ +MAL; 1991.08.06., $60^{\star}$ 8ᄋ, MJ, +MAL; 1988.08.16., 20, MJ, +MAL - Igal: 1984.07.23., 180 160, TS - Inke: 1957.09.05., 2O, ES - Kis-Balaton: 1956.09.10., 1Q, JT; 1979.06.17., $50^{\star} \quad 50, \quad \mathrm{CSM} ; 1979.06 .17 ., 130^{\star} 150, \mathrm{TS}$; 
1980.07.09., 10 10 10, DÁ; 1988.08.11., 50 $0^{\star}$, TS Kúti-őrház: 1975.07.15., 20 , TS; 1977.07.14., 10, TS, +TÁL; 1978.08.27., 30 50, TS; 1982.08.31., $40^{\star}$ 11Q, TS - Marcali: 1952.06.07., 1Q, SGY; 1955.05.10., 1Q, SGY - Nagy-berek: 1976.08.05., $30^{\pi} 5$, , TS; $1977.05 .02 ., 20^{\star}$, KÁ; 1977.09.05., $50^{\star}$ 3o, TS; 1977.09.10., 10 , TS; 1978.08.29., $30^{\star} 2$ 2ᄋ, TS - Nagy-gyótai-erdő: 1992.04.15., 10, TS - Nyugati-berek: 1989.06.26., $30^{\star}$ 50, TS - Potony: 1973.05.09., $10^{\star} 30$, TS; 1977.05.03., $40^{\star}$ 3०, TS; 1977.09.05., $10^{\star}$ 2Q, TS - Raglári-erdő: 1987.05.15., $10^{\star}$, TS - Ropolypuszta: 1988.05.31., $10^{\star} 2 Q$, TS, +MAL; 1988.05.28., 1@, TS, +MAL; 1988.05.29., 1O, TS, +MAL; 1988.08.18., $10^{\star} 30$, HA - Siófok: 1969.07.29., $30^{\star}$ 1O, TS; 1984.06.30., 10 $0^{\star}$, SGY; 1984.08.12., 1Q, SGY; 1986.08.22., 1O, SGY Somogytarnóca: 1984.07.30., $380^{\pi} 22$, TS Zamárdi: 1957.07.01., 10 2Q, SÁ; 1958.05.01., 40 , KZ; 1980.07.27., 4ㅇ, SÁ.

Sphaerophoria taeniata (Meigen, 1822) Balatonberény: 1984.07.14., $10^{\pi} 1$, SGY Balatonszemes: 1957.06.18., 2O, SÁ - Bankó-hegy: 1988.07.24., 10 10, TS - Barcsi-borókás (Darány):

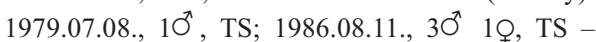
Hosszúvíz: 1989.07.18., 20， MJ, +MAL; 1988.07.21., 10 , MJ, +MAL; 1989.07.22., $10^{\star}$, MJ, +MAL; 1989.07.24., 10 ${ }^{\star}$, MJ +MAL - Igal: 1984.07.23., 10 $0^{\top}$, TS - Kis-Balaton: 1980.07.09., 10, DÁ - Kúti-őrház: 1982.08.31., 20, TS - Nagyberek: 1977.05.02., 10 , KÁ - Potony: 1973.05.09., 1O, TS - Ropolypuszta: 1985.08.14., $10^{\star} 2 \mathrm{O}$, TS; 1988.08.18., 10 $0^{\star}$, HA - Siófok: 1969.07.29., 20 TS.

Sphaerophoria virgata Goeldlin de Tiefenau, 1974 - Barcsi-borókás (Darány): 1973.05.09., 50, TS; 1975.09.04., 10 $0^{\star}$, TS; 1976.08.05., 10 1976.08.16., $10^{\star}$, BZS; 1978.08.27., 10 $10^{\star}$, TS; 1978.08.29., 10, TS - Kúti-őrház: 1978.08.27., 30, TS - Nagy-berek: 1976.08.05., 10 , TS; 1978.08.29., $20^{\pi}$, TS.

Sphegina elegans Schummel, 1843 - Enyezdirakodó: 1988.07.24., 10 $0^{\star}$, TS.

Spilomyia diophthalma (Linnaeus, 1758) - Barcsi-borókás (Darány): 1975.09.03., 1@, TS - Kúti-őrház: 1975.07.15., $10^{\star}$ 10, TS; 1975.09.04., 10 $0^{\star}$, TS; 1975.09.06., 2O, TS; 1978.08.27., 10, TS - Nagy-berek: 1978.08.29., 10, TS; 1982.08.31., 10, TS.

Syritta pipiens (Linnaeus, 1758) Balatonberény: 1964.07.08., 10, SÁ; 1986.07.14.,
10 $0^{\star}$, SGY - Balatonfenyves: 1957.08.06., 140 7O, ES; 1983.08.28., 30 10, SZD; 1986.06.30., 10, SGY - Balatonföldvár: 1968.08.14., $10^{\star}$ 1Q, TS Balatonőszöd: 1962.08.09., 10 $0^{\star}$, MV - Baláta-tó: 1989.10.06., 60 20, TS; 1994.06.29., $110^{\star}$ 4Q, TS; 1994.07.01., 20 30, TS, +MAL - Barcsi-borókás (Barcs): 1977.09.05., 10 30, TS - Barcsi-borókás (Darány): 1986.08.11., 10 10, TS - Csikota: 1978.08.29., $20^{\star} 3$ O , TS; 1984.07.31., $40^{\star}$ 2O, TS Erdősház-I.: 1988.07.15., $10^{\star}$ 1Q, TS, +MAL Hosszúvíz: 1989.07.22., 1@, MJ, +MAL; 1989.09.08., 10 $0^{\star}, \mathrm{MJ}+\mathrm{MAL}$ - Igal: 1984.07.23., $60^{\star}$ 2Q, TS - Kis-Balaton: 1956.09.10., $10^{\top} 1$ 1Q, JT; 1979.06.17., 1, CSM; 1979.06.17., 10 30, TS - Kúti-őrház: 1978.08.27., $20^{\star}$ 1Q, TS; 1978.08.28., $10^{\star}$ 2ᄋ, TS - Lipótfa: 1986.05.09., $20^{\star} 1$ 1Q, TS - Lugierdő (Potony): 1977.05.03., $10^{\star}$ 2Q, TS - Nagy-berek: 1977.09.05., $10^{\pi} 2$ Q, $\mathrm{TI}$; 1977.09.05., $30^{\pi} 1$ 1 , TS; 1978.08.29., $20^{\star}$ 1Q, TS - Potony: 1977.05.03., $30^{\star} 30$, KÁ; 1977.05.03., 140 100, TS - Siófok: 1969.07.29., $50^{\star} 1$ 1,$\quad$ TS - Somogytarnóca: 1984.07.30., 140 11O, TS - Zamárdi: 1957.07.02., 10, SÁ; 1980.07.27., 1ㅇ, SÁ.

Syrphus ribesii (Linnaeus, 1758) Balatonfenyves: 1957.08.12., 10 $0^{\star}$, ES - Balatonlelle: 1962.08.16., $10^{\star} 1$ 1, MF - Baláta-tó: 1989.10.06., 1Q, TS; 1994.06.29., 2Q, TS; 1994.07.01., 1@, TS, +MAL; 1997.06.17., 10, MJ - Bankó-hegy: 1988.07.24., 3O, TS - Barcsi-borókás (Darány): 1986.08.11., 10 10 10, TS - Erdősház-I.: 1987.06.21., 1ᄋ, TS, +MAL; 1988.05.30., 10, PJ; 1988.07.09., 1@, TS, +MAL - Hosszúvíz: 1989.07.16., 20 1 10, MJ, +MAL; 1988.07.21., 1Q, MJ, +MAL; 1989.07.30., $10^{\star}, \mathrm{MJ}+\mathrm{MAL}$ - Igal: 1984.07.23., $10^{\star}$ 3Q, TS - Kis-Balaton: 1986.07.15., 10 $0^{\top}, \mathrm{PA}$; 1986.07.15., 10 , PL - Kishárságy: 1986.05.09., 1Q, TS - Kúti-őrház: 1975.07.15., 3Q, TS - Nagy-berek: 1977.09.05., $20^{*}$ 4Q, TI; 1977.09.05., $10^{*} 3$ \%, TS; 1978.08.29., $10^{\star}$ 3Q, TS - Potony: 1977.05.03., 1Q, KÁ; 1977.05.03., 10 $0^{\star}$, TS - Somogytarnóca: 1984.07.30., $20^{\star} 1$ 1Q, TS - Szenna: 1984.07.22., $20^{\star}$ 10, TS; 1986.05.09., $10^{\Uparrow} 10$, TS.

Syrphus torvus Osten Sacken, 1875 - Barcsi-borókás (Darány): 1986.08.11., 1Q, TS - Csikota: 1977.05.02., 10 2O, KÁ; 1977.05.02., 3O, TS - Erdősház-I.: 1987.10.07., 10 1Q, TS, +MAL - Kútiőrház: 1975.07.15., $10^{\pi} 20$, TS - Nagy-berek: 
1973.05.09., $20^{\star}$ 1O, TS; 1977.05.02., 1O, KÁ; 1978.08.29., 10 2O, TS - Nagy-gyótai-erdő: 1992.04.15., 30 , TS - Potony: 1977.09.05., $10^{\star}$ 4우, TS - Ropolypuszta: 1985.08.14., 2O, TS - Zamárdi: 1960.05.11., 1o, A.

Syrphus vitripennis Meigen, 1822 Balatonfenyves: 1957.08.06., 20, ES Balatonföldvár: 1968.08.14., 1Q, TS - Balatonlelle: 1962.08.16., 1Q, MF - Baláta-tó: 1994.07.01., $10^{\star}$ 5Q, TS, +MAL; 1994.07.05., 30 $30^{\pi}$ 8Q, TS; 1997.06.12., 9Q, MJ; 1997.06.17., 2O, MJ; 1998.09.23., 4Q, MJ - Bankó-hegy: 1988.07.24., $20^{\star}$ 4Q, TS - Csikota: 1984.07.31., $10^{\star}$ 4Q, TS - Erdősház-I.: 1987.09.09., 1Q, TS, +MAL; 1987.09.26., $10^{\star}$ 10, TS, +MAL; 1988.06.02., $10^{\star} 10$, TS, +MAL; 1987.06.08., 1Q, TS, +MAL; 1988.06.18., 1O, TS, +MAL; 1988.07.08., 1@, TS, +MAL - Erdősház-I.: 1987.09.15., 1Q, TS, +MAL; 1987.09.26., $10^{\star} 1 \%$, TS, +MAL; 1988.06.15., $10^{\star} 1$ \%, TS, +MAL; 1988.06.16., 1Q, TS, +MAL; 1988.06.17., 1Q, TS, +MAL - Hosszúvíz: 1988.08.17., 1O, MJ, +MAL; 1989.07.16., 3Q, MJ, +MAL; 1989.07.20., $20^{\star} 3 Q$, MJ, +MAL; 1989.07.23., 1Q, MJ, +MAL; 1989.08.12., 10, MJ, +MAL - Igal: 1984.07.23., $30^{\star}$ 2O, TS - Kishárságy: 1986.05.09., 1Q, TS - Kúti-őrház: 1975.07.15., 110 7Q, TS; 1975.07.16., $10^{\star}$ 3Q, TS - Lipótfa: 1986.05.09., 1@, TS - Nagy-berek: 1977.09.05., $10^{\pi} 30$, TS - Nagy-gyótai-erdő: 1992.04.15., $10^{\star}$ 1O, TS - Ropolypuszta: 1988.08.18., $10^{\star} 2$ 2Q, HA - Somogytarnóca: 1984.07.30., 50 30, TS.

Temnostoma bombylans (Fabricius, 1805) Potony: 1977.05.03., 10 $0^{\star}$, TS - Ropolypuszta: 1988.05.16., 10 $0^{\star}$, TS, +MAL; 1988.05.17., 20 , TS, +MAL; 1988.05.31., 10 $0^{\star}$, TS, +MAL.

Temnostoma vespiforme (Linnaeus, 1758) Ropolypuszta: 1988.07.23., 10 $0^{*}$, TS.

Triglyphus primus Loew, 1840 - Erdősház-I.: 1987.08.07., 1@, TS, +MAL - Hosszúvíz: 1989.07.22., 10 $0^{\star}, \mathrm{MJ},+\mathrm{MAL}$

Tropidia scita (Harris, 1780) - Baláta-tó: 1994.06.29., $20^{\star} 1$ 1, $\mathrm{TS}$; 1994.07.01., $10^{\star}$, TS, +MAL - Boronka: 1990.07.03., 1@, MJ, +MAL Enyezdi-rakodó: 1988.07.24., $10^{\pi} 3$ 3o, TS Fonyódliget: 1986.06.05., 10 , OV.

Volucella bombylans (Linnaeus, 1758) - Balátató: 1994.06.29., $10^{\star}$, TS - Bankó-hegy: 1988.07.24., $10^{\star} 2$ 2Q, TS - Cseberki-erdő:
1988.07.23., 1O, TS - Kis-Balaton: 1979.06.17., 1@, TS - Potony: 1977. 05.03., 10 , TS - Zamárdi: 1965.08.28., 1O, ML.

Volucella inanis (Linnaeus, 1758) - Baláta-tó: 1994.07.05., 10 , TS - Bankó-hegy: 1988.07.24., 10 $0^{\star}$, TS - Kúti-őrház: 1978.08.27., $20^{\star}$ 1Q, TS Potony: 977.05.03., $10^{\pi} 1$, TS - Ropolypuszta: 1985.08.14., $10^{\pi}$, TS.

Volucella inflata (Fabricius, 1794) - Böhönye: 1987.06.29., 1Q,, TS, +MAL - Kúti-őrház: 1978.08.27., $10^{\pi} 3$, TS.

Volucella pellucens (Linnaeus, 1758) - Baláta-tó: 1994.07.01., 1O, TS, +MAL;1994.07.05., 40 1\%, TS - Bankó-hegy: 1988.07.24., 40 , TS - Potony: 1977.09.05., $10^{\star} 1$ 1Q, TS - Szerenkei-erdő: 1988.07.23., $10^{\pi} 2$, TS.

Volucella zonaria (Poda, 1761) - Balatonlelle: 1962.08.16., 1Q, MF - Kardosfapuszta: 1980.08.06., $10^{\star}$, TS - Ropolypuszta: $1980.08 .06 ., 1$,, CSM Zamárdi: 1962.07.08., 10 1Q, ML; 1963.06.11., 10, ML. Xanthandrus comtus (Harris, 1780) - Baláta-tó: 1989.10.06., 10, TS - Potony: 1977.09.05., 30, TS.

Xanthogramma festivum (Linnaeus, 1758) Ropolypuszta: 1980.05.29., 10 10, TS - Zamárdi: 1958.05.01., $60^{\star} 3$ 3, KZ.

Xanthogramma laetum (Fabricius, 1794) Potony: 1977.05.03., 10, TS.

Xanthogramma pedisseguum (Harris, 1776) Balatonfenyves: 1957.08.06., $10^{\star}$ 10, ES - Balátató: 1994.06.29., 40 1Q, TS; 1997.06.12., 10, MJPotony: 1977.05.03., 1Q, KÁ - Ropolypuszta: 1985.08.14., 1Q, TS.

Xylota ignava (Panzer, 1798) - Barcsi-borókás (Darány): 1977.06.05., 10 , TS.

Xylota segnis (Linnaeus, 1758) - Balatonőszöd: 1959.08.04., 1@, MV - Baláta-tó: 1994.07.01., 1Q, TS, +MAL; 1994.07.05., $10^{\star}$ 2O, TS - Bankó-hegy: 1988.07.24., 1@, TS - Darány: 1982.06.23., 10 $10^{\star}, \mathrm{BF}$ - Erdősház-I.: 1988.05.30., 1Ǫ, PJ - Ropolypuszta: 1988.08.18., $10^{\star} 1$ 1 , HA.

Xylota sylvarum (Linnaeus, 1758) - Baláta-tó: 1998.07.10., $10^{\star} 2$ 2O, MJ - Enyezdi-rakodó: 1988.07.24., 2ᄋ, TS.

\section{Fejeslegyek (Conopidae)}

A dolgozat 17 fejeslégy faj adatait tartalmazza.

Conops ceriaeformis Meigen, 1824 - Lugi-erdő 
(Tótújfalu): 1995.07.11., $\quad 20^{\star} \quad 10, \quad$ TS Szentmihályhegy: 1995.07.10., 2O, TS, +MAL.

Conops quadrifasciatus Degeer, 1776 - BarcsiBorókás (Darány): 1982.08.05., 10 , WM 1982.08.31., 30 1@, TS - Erdei-dúlő: 1995.07.04., 1Q, TS, +MAL - Kúti-őrház: 1981.08.04., 1Q, UÁ Lankóci-erdő: 1995.07.10., $20^{\pi} 30$, TS, +MAL; 1995.09.04., 2Q, TS - Palinai-erdő: 1995.09.05., $10^{\star}$ 1@, TS - Ropolypuszta: 1988.07.22., 1@, TS, +MAL. Conops scutellatus Meigen, 1804 - BarcsiBorókás (Darány): 1982.08.31., 10 10, TS; 1986.08.11., 10 $0^{*}$, TS.

Conops vesicularis Linnaeus, 1761 - Lankócierdő: 1997.05.06., $20^{\star} 1$ 1 , TS.

Myopa buccata (Linnaeus, 1758) - Lankócierdő: 1995.05.03., $20^{\star}$ 1Q, TS - Soponyai-halastó: 1990.04.11., 1O, NL - Szentmihályhegy: 1995.05.03., $40^{\star} 10$, TS.

Myopa morio Meigen, 1804 - Berki-erdő: 1995.05.04., 3Q, TS - Kishárságy: 1986.05.09., 10, TS - Lankóci-erdő: 1995.05.03., 20 10, TS - Lugierdő (Tótújfalu): 1995.05.04., 10 Márcadópuszta: 1986.05.09., 10 $0^{\pi}$, TS - Mély-éger: 1990.05.02., 10 $0^{\star}$, TS - Palinai-erdő: 1995.05.03., 10 , TS - Ropolypuszta: 1988.07.14., 10, TS, + MAL.

Myopa occulta Meigen, 1824 - Erdei-dűlö: 1995.07.04., 30 10, TS.

Myopa polystigma Rondani, 1857 - Lankócierdő: 1993.05.04., 10 $0^{\star}$, TS.

Myopa stigma Meigen, 1824 - Pusztafalusi-dủlő: 1995.05.03., 10 $0^{\star}$, TS.

Myopa testacea (Linnaeus, 1767) - Lankócierdő: 1995.05.03., 20 1Q, TS; 1996.05.10., $10^{\star} 30$, TS; 1997.05.06., $20^{\star}$ 1Q, TS - Lugi-erdő (Tótújfalu): 1995.05.04., 4Q, TS - Ropolypuszta: 1988.07.03., 1o, TS, +MAL - 1988.07.22., 1@, TS, +MAL.

Physocephala vittata (Fabricius, 1794) - Berkierdő: 1995.09.04., 10 10, TS - Galabárdpuszta: 1989.07.10., 20 , JZS; 1989.08.18., 10 $0^{\star}$, JZS - Kerék-hegy: 1992.06.07., $10^{\star}$, TS - Lugi-erdő (Potony): 1995.07.11., 20 ${ }^{\star}$, TS - Szentmihályhegy: 1995.07.10., 10, TS, +MAL.

Sicus ferrugineus (Linnaeus, 1761) Galabárdpuszta: 1989.07.10., 1@, JZS - Homokpuszta: 1990.07.20., $10^{*} 10, \quad \mathrm{NL}$ - Lankócierdő:1995.07.10., 30 2Q, TS, +MAL - Mély-éger: 1971.07.10., 10,$\quad$ TS - Mély-égeri-halastó: 1990.07.20., $10^{\star} 1$ 1, TS - Palinai-erdő: 1992.06.17., $10^{\star}$, TS - 1995.07.10., 30, TS - Pap-erdő:
1996.06.26., 1O, KE - Ropolypuszta: 1982.06.27., 10', TS; 1988.06.06., 2O, TS, +MAL; 1988.06.10., 1\%, TS, +MAL; 1988.06.14., 1Q, TS, +MAL; 1988.06.30., 30 10, TS, +MAL; 1988.07.14., $10^{\pi}$ 30 , TS, +MAL; 1988.07.22., $10^{\pi} 1$ \%, TS, +MAL Soponyai-halastó: $1990.07 .20 ., \quad 10^{\pi} 1$ Q,$\quad$ TS; 1991.07.31., 10 $0^{\pi}$, TS.

Thecophora atra (Fabricius, 1775) - Kétnyáriberek: 1995.07.10., 2O, TS - Lugi-erdő (Potony): 1995.07.11., 40 10, TS - Örtilos: 1995.09.04., 1Q, TS.

Thecophora melanopa Rondani, 1857 - Lankócierdő: 1995.07.10., 30, TS, +MAL - Ropolypuszta: 1988.08.14., $10^{\pi} 10$, TS, +MAL.

Thecophora pusilla (Meigen, 1824) - Lankócierdő: 1995.09.04., 1O, TS - Lugi-erdő (Tótújfalu): 1995.07.11., $10^{\pi} 2 \mathrm{O}, \quad \mathrm{TS}$ - Ropolypuszta: 1988.08.14., 10 $0^{\star}$, TS, +MAL.

Zodion cinereum (Fabricius, 1794) - Lankócierdő: 1995.07.10., 20 30, TS; 1995.09.04., 1@, TS - Ropolypuszta: 1988.06.21., 10 , TS, +MAL.

Zodion notatum (Meigen, 1804) - Ropolypuszta: 1988.07.14., 2Q, TS, +MAL - Szentmihályhegy: 1995.07.03., 1o, TS.

\section{Fürkészlegyek (Tachinidae)}

A dolgozat 96 fürkészlégy faj adatait tartalmazza, azonban a teljes anyag feldolgozása még nem történt meg.

Acemya acuticornis (Meigen, 1824) - Berki-erdő: 1996.05.1., 30 4Oे, TS - Kétnyári-berek: 1996.05.10., 3Q, TS - Lankóci-erdő: 1996.08.09., $10^{\pi}$ 2ᄋ, TS - Pusztafalusi-dülő: 1995.07.04., $20^{\star} 1$ 1 TS, +MAL.

Actia crassicornis (Meigen, 1824) - Baláta-tó: 1994.06.29., 4Q, TS - Lugi-erdő (Tótújfalu): 1996.05.11., 2Q, TS - Palinai-erdő: 1996.08.09., 10 3O, TS - Pusztafalusi-dűlő: 1995.07.04., 10 4O , TS, + MAL.

Actia infantula (Zetterstedt, 1844) - Berki-erdő: 1995.05.04., $20^{\star} 1$ \%, TS.

Aphria longilingua Rondani, 1861 - Lankócierdő: 1996.08.09., 2O, TS - Pusztafalusidűlő:1995.07.04., 2Q, TS, +MAL.

Aplomyia confinis (Fallén, 1820) - Erdei-dúlő: 1995.07.04., $20^{\star} 5$ Q, TS, +MAL.

Athrycia trepida (Meigen, 1824) - Pusztafalusidűlő: 1995.07.04., 30 1o, TS, +MAL.

Atylostoma tricolor (Mik, 1883) - Lankóci-erdő: 
1995.07.10., $20^{\star} 10$, TS, +MAL.

Bessa parallela (Meigen, 1824) - Baláta-tó: 1994.06.29., $10^{\star}$ 8@, TS - Erdei-dúlő: 1995.07.04., $10^{\pi} 4$, , TS, +MAL.

Billaea pectinata (Meigen, 1826) -

Szentmihályhegy: 1995.07.10., 40 10, TS, +MAL.

Bithia spreta (Meigen, 1824) - Palinai-erdő: 1995.07.10., 30 10, TS.

Blepharipa pratensis (Meigen, 1824) - Baláta-tó: 1994.07.01., 30 20, TS, +MAL - Pusztafalusi-dűlő: 1995.07.04., 10 $0^{\star}$, TS, +MAL.

Blepharipa schineri Mesnil, 1939 - Lankócierdő: 1995.07.10., 30 10, TS, +MAL.

Blondelia nigripes (Fallén, 1820) - Baláta-tó: 1994.06.29., 50 120, TS - 1994.07.01., 80 30, TS, +MAL - Pusztafalusi-dúlő: 1995.07.04., 30^ 2Q, TS, + MAL.

Carcelia bombylans (Robineau-Desvoidy, 1830) - Lugi-erdő (Potony): 1995.07.10., $20^{\star}$ 1O, TS.

Carcelia lucorum (Meigen, 1824) - Lankócierdő: 1995.07.10., 20 30, TS, +MAL.

Catharosia pygmaea (Fallén, 1815) Pusztafalusi-dúlő: 1995.07.04., 10 30, TS, +MAL. Ceromyia bicolor (Meigen, 1824) - Kétnyári-berek: 1995.07.10., 10 $0^{\pi}$, TS.

Ceromyia silacea (Meigen, 1824) - Örtilos: 1995.07.10., $10^{\star} 1$ o, TS.

Chetogena filipalpis Rondani, 1859 Szentmihályhegy: 1995.07.10., 10, TS, +MAL.

Chrysocosmius auratus (Fallén, 1820) - Balátató: 1994.07.01., 10त, TS, +MAL - Lankóci-erdő: 1995.07.10., $20^{\star} 10$, TS, +MAL.

Clytiomya continua (Panzer, 1798) Pusztafalusi-dủlő: 1995.07.04., 20 3Q, TS, +MAL.

Compsilura concinnata (Meigen, 1824) - Balátató: 1994.06.29., 60 80, TS; 1994.07.01., 30 30, TS, +MAL

Cylindromyia auriceps (Meigen, 1838) - Erdeidűlő: 1995.07.04., 10 20, TS, +MAL.

Cylindromyia bicolor (Olivier, 1812) - Baláta-tó: 1994.06.29., 10 $0^{\star}$, TS; 1994.07.01., $20^{\star} 1 \mathrm{~B}$, TS, +MAL - Kétnyári-berek: 1995.07.10., 20 1Q, TS.

Cylindromyia brassicaria (Fabricius, 1775) Baláta-tó: 1994.06.29., 20 4Q , TS.

Cyzenis albicans (Fallén, 1810) - Lankóci-erdő: 1995.05.03., 10 $0^{*}$, TS.

Dexia rustica (Fabricius, 1775) - Erdei-dúlő: 1995.07.04., 10 10, TS, +MAL.

Dinera carinifrons (Fallén, 1816) - Balátató:1994.07.01., 10 $0^{\star}$, TS, +MAL.

Dufouria chalybeata (Meigen, 1824) -
Pusztafalusi-dűlő: 1995.07.04., 30, TS, +MAL. Ectophasia crassipennis (Fabricius, 1794) Baláta-tó: 1994.06.29., 30, TS; 1994.07.01., 30²0\%, TS, +MAL. Eliozeta helluo (Fabricius, 1805) Szentmihályhegy: 1995.07.10., 20 , TS, +MAL Elomyia lateralis (Meigen, 1824) - Baláta-tó: 1994.07.01., 10, TS, +MAL. Epicampocera succincta (Meigen, 1824) Baláta-tó: 1994.06.29., 10 10, TS. Eriothrix argyreata (Meigen, 1824) - Holt-Dráva: 1995.09.04., 1Q, TS.

Eriothrix rufomaculata (De Geer, 1776) - Örtilos: 1995.09.04., 20 $0^{\top}$, TS

Ernestia rudis (Fallén, 1810) - Erdei-dűlő: 1995.07.04., 2Q, TS, +MAL. Erythrocera nigripes (Robineau-Desvoidy, 1830) - Lankóci-erdő: 1995.07.10., 2Q, TS, +MAL. Eumea linearicornis (Zetterstedt, 1844) Szentmihályhegy: 1995.07.10., 20, TS, +MAL.

Exorista larvarum (Linnaeus, 1758) - Baláta-tó: 1994.07.01., $10^{\star} 30$, TS, +MAL - Palinai-erdő: 1995.05.03., 20, TS.

Exorista rustica (Fallén, 1810) - Baláta-tó: 1994.06.29., $30^{\star} 1$ 1 , TS.

Frontina laeta (Meigen, 1824) - Lankóci-erdő: 1995.07.10., 10 $0^{\star}$, TS, +MAL.

Gonia divisa Meigen, 1826 - Palinai-erdő: 1995.05.03., 50 3o, TS.

Gonia ornata Meigen, 1826 - Baláta-tó: 1994.07.01., 2Q, TS, +MAL - Pusztafalusi-dűlő: 1995.07.04., $20^{\pi} 6$ \%, TS, +MAL.

Gonia vacua Meigen, 1826 - Szentmihályhegy: 1995.07.10., $30^{\star} 1 \mathrm{Q}$, TS, +MAL.

Gymnochaeta viridis (Fallén, 1810) - Lugi-erdő (Tótújfalu): 1995.05.04., 10 20, TS.

Gymnosoma clavatum (Rohdendorf, 1947) - Erdei-dúlő: 1995.07.04., 30, TS, +MAL Pusztafalusi-dűlő: 1995.07.04., 20 1ơ, TS, +MAL. Gymnosoma nitens Meigen, 1824 - Holt-Dráva: 1995.09.04., 10 $0^{\star}$, KE.

Gymnosoma nudifrons Herting, 1966 Szentmihályhegy: 1995.07.10., 40 10, TS, +MAL. Gymnosoma rotundatum (Linnaeus, 1758) Baláta-tó: 1994.06.29., 5O, TS; 1994.07.01., 20 30, TS, +MAL.

Hemyda obscuripennis (Meigen, 1824) - Lugierdő (Tótújfalu): 1995.07.11., 30, TS.

Leskia aurea (Fallén, 1820) - Baláta-tó: 1994.06.29., 2O, TS.

Leucostoma simplex (Fallén, 1815) - Lugi-erdő (Tótújfalu): 1995.07.1., 10 20, TS. 
Linnaemyia media Zimin, 1954 - Lankóci-erdő: 1995.07.10., 10 $0^{*}$, TS, +MAL.

Linnaemyia picta (Meigen, 1824) - Baláta-tó: 1994.06.29., $110^{\pi}$ 5o, TS

Linnaemyia vulpina (Fallén, 1810) - Lugi-erdő (Potony): 1995.07.11., 10 20, TS.

Loewia phaeoptera (Meigen, 1824) - Lugi-erdő (Potony): 1995.07.10., 2O, TS.

Lydella grisescens Robineau-Desvoidy, 1830 Erdei-dủlő: 1995.07.04., $10^{\star}$ 3Q, TS, +MAL Szentmihályhegy: 1995.07.10., 20, TS, +MAL.

Lydella stabulans (Meigen, 1824) - Baláta-tó: 1994.07.01., 20 $0^{\star}$, TS, +MAL - Pusztafalusi-dűlő: 1995.07.04., 20, TS, +MAL

Macquartia tenebricosa (Meigen, 1820) Lankóci-erdő: 1995.07.10., 30 10, TS, +MAL.

Masicera silvatica (Fallén, 1810) - Lugi-erdő (Tótújfalu): 1995.07.11., 10 40, TS.

Meigenia dorsalis (Meigen, 1824) - Baláta-tó: 1994.07.01., 60 20, TS, +MAL - Szentmihályhegy: 1995.09.18., 10, TS.

Meigenia mutabilis (Fallén, 1810) - Baláta-tó: 1994.06.29., 4O 2Q, TS - Erdei-dűlő: 1995.07.04., $60^{\pi} 3 \mathrm{O}, \mathrm{TS},+\mathrm{MAL}$.

Meigenia uncinata Mesnil, 1967 - Erdei-dűlő: 1995.07.04., 10 2Q, TS, +MAL.

Meriania puparum (Fabricius, 1794) - Lankócierdő: 1995.07.10., 20, TS, +MAL

Mintho rufiventris (Fallén, 1816) - Örtilos: 1995.07.04., 30 10, TS.

Pales pavida (Meigen, 1824) - aláta-tó: 1994.06.29., 2O, TS; 1994.07.01., 2O, TS, +MAL Lankóci-erdő: 1995.07.10., 60 10, TS, +MAL.

Peleteria varia (Fabricius, 1794) - Kétnyári-berek: 1995.07.10., 20", TS

Peribaea tibialis (Robinaeu-Desvoidy, 1851) Baláta-tó: 1994.06.29., 10 4O, TS; 1994.07.01., 40 10 , TS, +MAL

Periscepsia carbonaria (Panzer, 1798) Lankóci-erdő: 1995.07.10., $10^{\star}$ 4O, TS, +MAL.

Phania funesta (Meigen, 1824) - Baláta-tó: 1994.06.29., 10 $0^{\star}, \mathrm{TS} ; 1994.07 .01 ., 10^{\star}$ 40, TS, +MAL - Erdei-dủlő: 1995.07.04., 20 10 10, TS, +MAL - Pusztafalusi-dúlő: 1995.07.04., 60 20, TS, +MAL - Szentmihályhegy: 1995.07.10., 60 2O, TS, + MAL.

Phasia obesa (Fabricius, 1798) - Baláta-tó: 1994.06.29., 10 10 1Q, TS - Erdei-dúlő: 1995.07.04., $50^{\top} 2 \mathrm{O}, \mathrm{TS},+\mathrm{MAL}$

Phasia oblonga (Robineau-Desvoidy, 1830) Lankóci-erdő: 1995.07.10., 30 40, TS, +MAL.

Phasia subcoleoptrata (Linné, 1767) - Berki-erdő: 1995.09.04., 20, TS.

Phorocera silvestris (Robineau-Desvoidy, 1863) - Lankóci-erdő: 1995.07.10., 10, TS, +MAL.
Phryxe nemea (Meigen, 1824) - Baláta-tó: 1994.06.29., 10 $10^{\pi}$, TS.

Phryxe vulgaris (Fallén, 1810) - Baláta-tó: 1994.06.29., 50 20, TS; 1994.07.01., 30 10, TS, +MAL - Erdei-dúlő: 1995.07.04., 30 10 10, TS, + MAL.

Phyllomyia volvulus (Fabricius, 1794) Szentmihályhegy: 1995.07.10., 10 , TS, +MAL.

Ramonda prunaria (Rondani, 1861) - Lankócierdő: 1995.07.10., 30 20, TS, +MAL.

Siphona cristata (Fabricius, 1805) Pusztafalusi-dúlő: 1995.07.04., 10 30, TS, +MAL.

Siphona geniculata (De Geer, 1776) - Baláta-tó: 1994.06.29., 10 $0^{\star}$, TS; 1994.07.01., 20 , TS, +MAL Erdei-dúlő: 1995.07.04., 70 10, TS, +MAL.

Siphona hungarica Andersen, 1984 - Lankócierdő: 1995.07.10., 20 , TS, +MAL.

Siphona maculata Staeger in Zetterstedt, 1849 . Baláta-tó: 1994.07.01., $10^{\pi} 2 \mathrm{O}, \mathrm{TS},+\mathrm{MAL}-$ Pusztafalusi-dűlő: 1995.07.04., 20 10, TS, +MAL.

Solieria fenestrata (Meigen, 1824) - Örtilos: 1995.09.04., $10^{\pi}$ 20, TS.

Solieria pacifica (Meigen, 1824) - Lankóci-erdő: 1995.07.10., 2O, TS, +MAL

Spallanzania hebes (Fallén, 1820) - Lugi-erdő (Tótújfalu): 1995.07.11., 40 10, TS

Sturmia bella (Meigen, 1824) - Baláta-tó: 1994.07.01., 10 50, TS, +MAL - Lankóci-erdő: 1995.07.10., 30 4O, TS, +MAL.

Tachina fera (Linnaeus, 1758) - Baláta-tó: 1994.06.29., 60 20, TS; 1994.07.01., 20, TS, +MAL - Erdei-dúlő: 1995.07.04., 20 60, TS, +MAL - Pusztafalusi-dűlő: 1995.07.04., 30 50, TS, +MAL - Szentmihályhegy: 1995.07.10., 40 10, TS, + MAL.

Tachina grossa (Linnaeus, 1758) Szentmihályhegy: 1995.05.03., 10 , TS, +MAL.

Tachina magnicornis (Zetterstedt, 1844) Baláta-tó: 1994.07.01., $30^{*}$ 20, TS, +MAL Lankóci-erdő: 1995.07.10., 10, TS, +MAL.

Tachina nupta (Rondani, 1859) - Dráva-hullámtér (Vízvár): 1995.07.10., $20^{\star 1} 1$ \%, TS.

Tachina ursina Meigen, 1824 - Lankóci-erdő: 1995.05.03., 10 $0^{\top}$, TS.

Thelaira nigripes (Fabricius, 1794) Pusztafalusi-dűlő: 1995.07.04., 2O, TS, +MAL.

Voria ruralis (Fallén, 1810) - Baláta-tó: 1994.07.01., $20^{\star} 1$ 1O, TS, +MAL - Erdei-dúlö: 1995.07.04., $20^{\star} 30$, TS, +MAL.

Zaira cinerea (Fallén, 1810) - Lankóci-erdő: 1995.07.10., 40 10, TS, +MAL - Szentmihályhegy: 1995.07.10., $20^{\star} 1 \mathrm{Q}$, TS, +MAL.

Zenillia libatrix (Panzer, 1798) - Pusztafalusidúlő: 1995.07.04., $10^{\star}$ 30, TS, +MAL.

Zeuxia cinerea Meigen, 1826 - Palinai-erdő: 
1995.07.04., $20^{\star}$, TS.

\section{Irodalom}

Ábramám L. (2001): Somogy fauna katalógusa - Nat. Somogy. 1: 1-494.

Dévai Gy. - Harangi J. - Miskolczi M. (1996): BioTér 1.42 Program.

MAJeR J. (2001a): Somogy megye katonalegyeinek katalógusa (Diptera: Stratiomyidae) - Nat. Somogy. 1: 395-397.

MAJER J. (2001b): Somogy megye bögölyeinek katalógusa (Diptera: Tabanidae) - Nat. Somogy. 1: 399-404.

TóтH S. (1996): Adatok a Boronka-melléki Tájvédelmi Körzet bögöly és katonalégy faunájához (Diptera: Tabanidae, Stratiomyidae) - Somogyi Múz. Közlem., 12: 263-270.

То́тн S. (2001a): Somogy megye lószúnyogjainak katalógusa (Dipera: Tipulidae) - Nat. Somogy. 1: 377-379.

То́тн S. (2001b): Somogy megye iszapszúnyogjainak katalógusa (Diptera: Limoniidae) - Nat. Somogy. 1: $381-382$

То́тн S. (2001c): Somogy megye csípőszúnyogjainak katalógusa (Diptera: Culicidae) - Nat. Somogy. 1: $383-388$

Tóth S. (2001d): Somogy megye tőröslegyeinek katalógusa (Diptera: Therevidae) - Nat. Somogy. 1: 409-410.

Tóтн S. (2001e): Somogy megye pöszörlegyeinek katalógusa (Diptera: Bombyliidae) - Nat. Somogy. 1: $411-412$.

Tótн S. (2001f): Somogy megye zengőlegyeinek katalógusa (Diptera: Syrphidae) - Nat. Somogy. 1: 413-422. TótH S. (2001g): Somogy megye fejeslegyeinek katalógusa (Diptera: Conopidae) - Nat. Somogy. 1: 423-424. 
Tо́тн S. (2001h): Somogy megye fürkészlegyeinek katalógusa (Diptera: Tachinidae) - Nat. Somogy. 1: $427-434$.

\section{Data to the fly (Diptera) fauna in Somogy County}

\section{SÁNDOR TÓTH}

In the past couple of decades, the collection of certain fly (Diptera) families in Somogy County was carried out with varying intensity. The investigation started with the study of the fly fauna of the Barcsi Landscape Protection Area in the second half of the 1970's and later it was carried on in the Zselic, in the Boronka-melléki Landscape Protection Area, along the River Dráva (later the Duna-Dráva National Park). Nowadays investigations are under way in the Látrányi Nature Protection Area. The results of the investigation were published in several documents, most recently in the "Catalogue of the Fauna of Somogy County" (ÁBRAHÁm 2001). Since the complete faunistical data could not be published in this catalogue due to its limited size, it is highly expedient to present the basic unpublished data hereby. The study contains the data of 373 species belonging to the following 7 families: Stratiomyidae (32 species), Bombyliidae (21 species), Therevidae (1 species), Tabanidae (29 species), Syrphidae (177 species), Conopidae (17 species), Tachinidae (96 species).

Author's address:

Dr. Sándor TóтH

H-8420 Zirc

Széchenyi u. 2.

HUNGARY 